\title{
Aeroelastic Analysis of a Distributed Electric Propulsion Wing
}

\author{
Steven J. Massey*, Bret K. Stanford, Carol D. Wieseman; and Jennifer Heeg ${ }^{\ddagger}$ \\ NASA Langley Research Center, Hampton, VA 23681-2199
}

\begin{abstract}
An aeroelastic analysis of a prototype distributed electric propulsion wing is presented. Results using MSC Nastran $^{\text {TM }}$ doublet lattice aerodynamics are compared to those based on FUN3D Reynolds Averaged NavierStokes aerodynamics. Four levels of grid refinement were examined for the FUN3D solutions and solutions were seen to be well converged. It was found that no oscillatory instability existed, only that of divergence, which occurred in the first bending mode at a dynamic pressure of over three times the flutter clearance condition.
\end{abstract}

\section{Nomenclature}

$\begin{array}{ll}\text { Latin Symbols } \\ c & \text { reference chord, in } \\ C_{D} & \text { drag coefficient, } \frac{D}{q_{\infty} S} \\ C_{L} & \text { lift coefficient, } \frac{L}{q_{\infty} S} \\ C_{m} & \text { pitching moment coefficient, } \frac{M_{Y}}{q_{\infty} S c} \\ C_{p} & \text { coefficient of pressure, } \frac{p-p_{\infty}}{q_{\infty}} \\ D & \text { drag, lb } \\ \Delta C_{p} & C_{p}(\text { lower surface })-C_{p}(\text { upper surface), } \\ & C_{p} \text { (ultra fine)- } C_{p}(\text { current }) \\ d Z & \text { wingtip displacement in the } Z \text { direction, in } \\ L & \text { lift, lb } \\ M & \text { Mach number } \\ M_{Y} & \text { pitching moment, lb } \cdot \text { in } \\ p & \text { pressure, psi } \\ q & \text { dynamic pressure, } \frac{1}{2} \rho u^{2}, \text { psi } \\ R e & \text { unit Reynolds number, } 1 / \text { in } \\ S & \text { reference area, in }{ }^{2} \\ T & \text { temperature, }{ }^{\circ} \mathrm{R} \\ u & \text { velocity, in/sec }\end{array}$

$\begin{array}{ll}\text { W } & \text { deflection in normal direction, in } \\ \bar{x}_{c p} & \text { root chord station of center of pressure } \\ \mathrm{X} & \text { axial direction } \\ y^{+} & \text {dimensionless, sublayer-scaled wall coordi- } \\ & \text { nate of first node away from surface } \\ \mathrm{Y} & \text { spanwise direction } \\ \mathrm{Z} & \text { normal direction } \\ \text { Greek Symbols } \\ \alpha & \text { angle of attack, } \\ \rho & \text { density, slugs/in }{ }^{3} \\ \theta & \text { wingtip twist, }\end{array}$

\section{Introduction}

$\mathrm{N}_{\mathrm{N}}$ unsteady Reynolds-averaged Navier-Stokes analysis, internally coupled with a linear modal structural routine $\mathrm{A}_{\text {for aeroelastic effects, is compared to a finite element structural analysis with doublet lattice aerodynamics for the }}$ wing of an early version ${ }^{\S}$ of the X-57 Maxwell ${ }^{1}$ flight demonstrator, previously known as SCEPTOR, ${ }^{2}$ Figure 1 . The wing is currently in the design stage, so the analysis results presented correspond to those conducted in this preliminary stage and should not be interpreted as predictions for the final design of the as-built vehicle. The X-57 wing relies on distributed electric propulsion ${ }^{3,4}$ to provide the needed lift for takeoff while allowing for a higher aspect ratio wing with lower planform area that is more efficient in cruise. During cruise, the inboard high lift propellers ${ }^{5,6}$ are stowed $^{7}$ to reduce drag. Present computations do not include any propellers, but future efforts will model the wing tip propellers with actuator disks. ${ }^{8,9}$

\footnotetext{
* Research Aerospace Engineer, Aeroelasticity Branch, MS 340, AIAA Senior Member

${ }^{\dagger}$ Senior Research Engineer, Aeroelasticity Branch, MS 340, AIAA Associate Fellow

¥Senior Research Engineer, Aeroelasticity Branch, MS 340, AIAA Senior Member

$\S$ OML Revision 3.3, Structures DOE9
} 


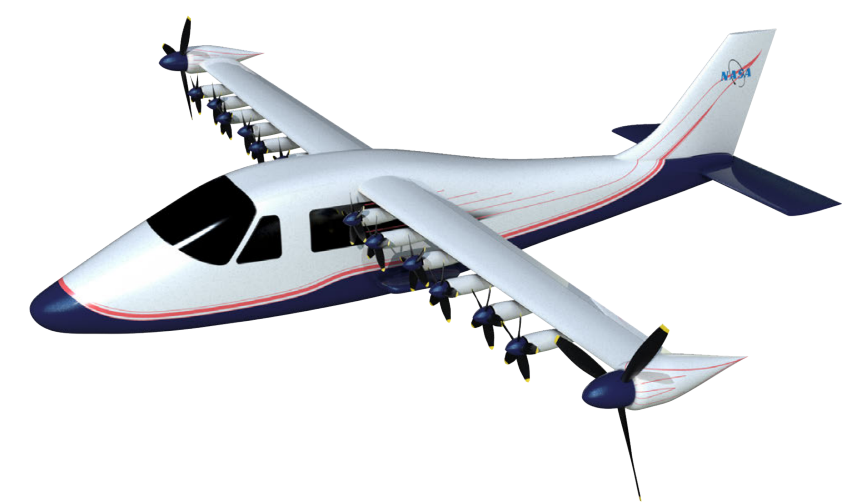

Figure 1: Rendering of X-57 flight demonstrator, revision 3.3.

\section{Computational Methodology}

\section{A. FEM and Linear Aeroelastic Modeling Details}

Structurally, the wing is modeled as a spar-rib wingbox, with symmetry enforced at the centerline and pinned at its root. The wingbox is composed of three full-depth spars, 14 full or partial-chord ribs, and upper and lower wing skins. These members are all modeled with linear quadrilateral shell elements, as laminate carbon fiber composites with a foam core. Rib stiffeners and skin stringers are modeled with aluminum eccentric beam elements. A trailing edge high-lift wing flap is similarly modeled as a spar-rib box, and connected to the main wingbox with interpolation elements.

Motor nacelles (six total under a single wing, plus one at the wingtip) are also modeled with quadrilateral shell elements, and connected to the main wingbox (namely to the skin-rib and skin-spar attachment lines) via interpolation elements. Inertial representations of the motors themselves are modeled with lumped masses, and connected to the surrounding nacelles with interpolation elements. Pylons are also modeled for under-wing nacelles, as flat plates discretized with quadrilateral elements.

The resulting structure is modeled in Nastran, ${ }^{10}$ with a total of 55,000 elements, Figure 2a. Natural vibration mode shapes may be computed and exported (along with natural frequencies) to conduct aeroelastic analysis with FUN3D. Linear aeroelastic analysis, on the other hand, may be conducted within Nastran, via a doublet lattice ${ }^{11}$ aerodynamic analysis using 6,700 panels. For the linear analysis, the wing is modeled as a flat plate, and the jig shape geometric details are captured with a prescribed downwash distribution. Pylons are modeled as vertical flat plates, and nacelles are modeled as cruciforms, Figure $2 \mathrm{~b}$. The linear aerodynamic and structural models are connected via a finite plate spline model, with splining points located at rib-skin and spar-skin intersections. Note, to facilitate comparisons with FUN3D, the Nastran aeroelastic analyses in this paper are conducted without gravitational loading (external aerodynamic forces only). The structural design version used in this study is DOE 9. The structure has since been further refined, based in part on the results in this paper.

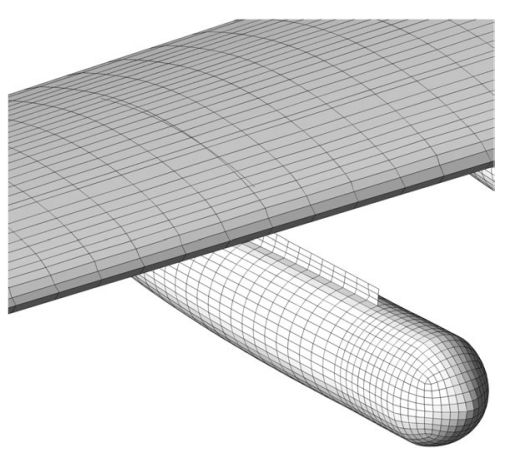

(a) Structural

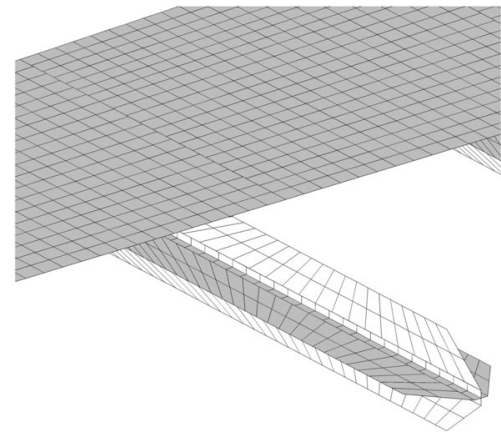

(b) Aerodynamic

Figure 2: Close up of surface grids for Nastran. 


\section{B. CFD Grid Generation}

A family of four grids (Figure 3) were created by the authors using Pointwise ${ }^{\mathrm{TM} 12}$ based on the guidelines from the 6th AIAA Drag Prediction Workshop. ${ }^{13}$ Successive refinements were created using a scale factor of $1 / 1.15$, with the exception of viscous spacing, where in accordance with best practices, it was held constant to maintain $y^{+} \approx 1$. The corresponding first cell height was 0.000122 inches and the geometric growth rate in the boundary layer spacing was 1.15 . Since the viscous grid spacing was held constant, the growth in nodes between grids was approximately $1.15^{2}$, yielding 6.7, 9.1 and 12.9 million nodes for the first three grids. After observing only minimal differences in the solutions between the second and third grid refinements, the fourth and fifth levels of refinement were skipped in favor of going straight to the sixth level (ultra fine) with 31.9 million nodes. Tetrahedrons in the boundary layer were also merged into triangular prisms to improve turbulence model performance. Significant savings in node count were also achieved by the use of spanwise stretching of cells in the boundary layer up to an aspect ratio of three. Farfield boundaries are located on a hemisphere 100 semispan lengths away from the wing surface. The grids in this study are based on OML revision 3.3. The OML has since been further refined and will be updated in future aeroelastic computations.

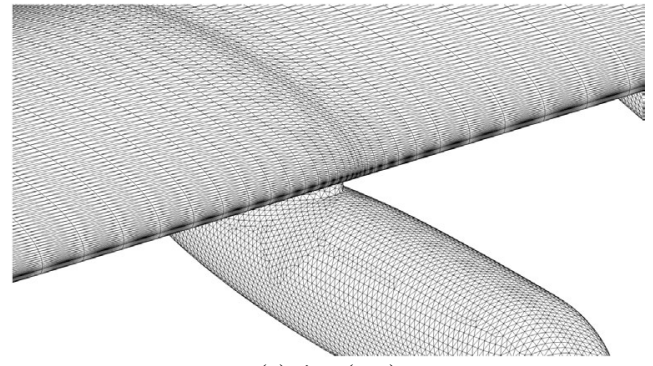

(a) tiny (top)

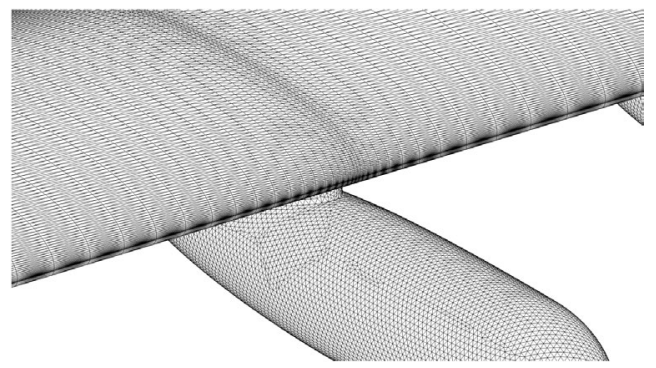

(c) coarse (top)

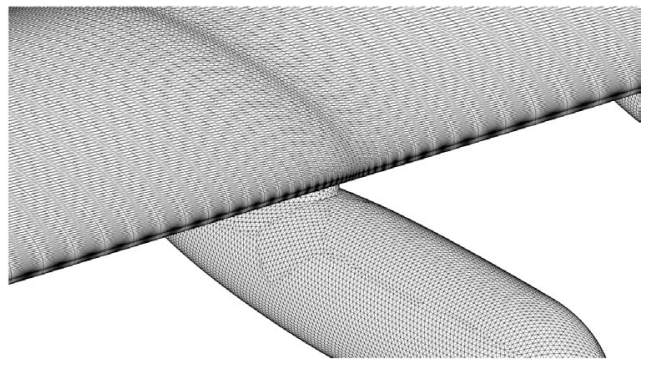

(e) medium (top)

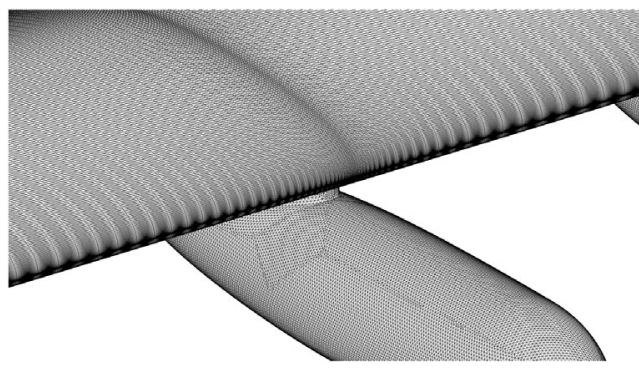

(g) ultra fine (top)

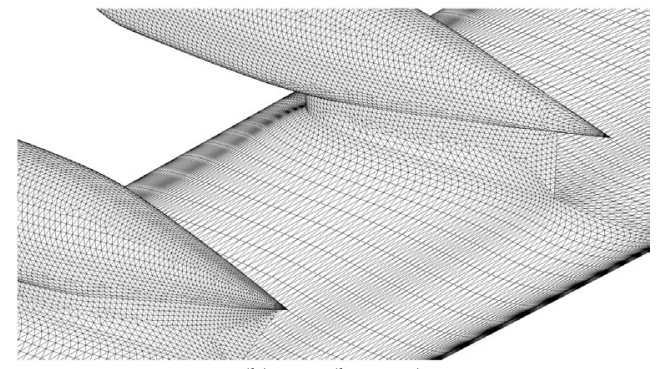

(b) tiny (bottom)

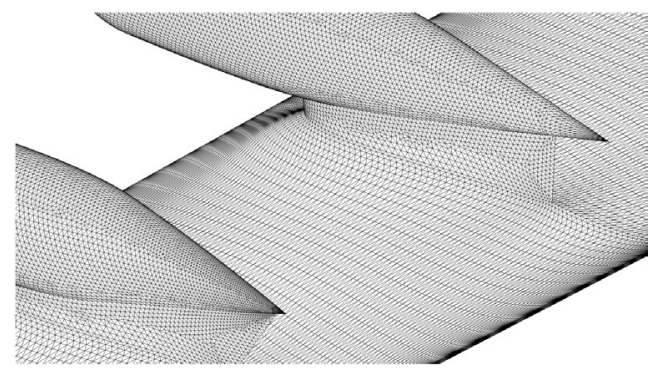

(d) coarse (bottom)

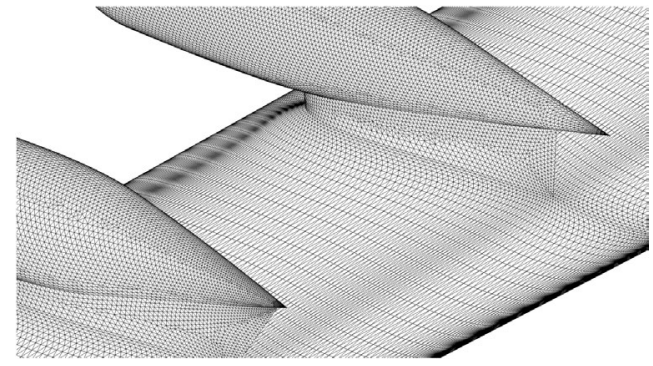

(f) medium (bottom)

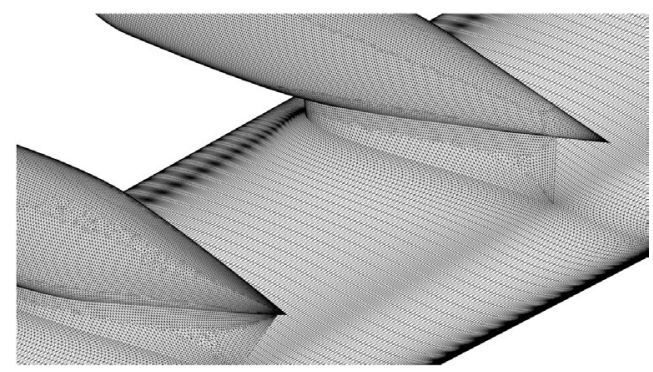

(h) ultra fine (bottom)

Figure 3: Top and bottom closeup views of FUN3D surface grids. 


\section{CFD Solver}

Solutions to the Reynolds-averaged Navier-Stokes equations are computed using the FUN3D ${ }^{14}$ flow solver. All solid surfaces are modeled with no-slip boundary conditions and farfield boundaries are of the Riemann invariant type. Turbulence closure is obtained using the Spalart-Allmaras ${ }^{15}$ one-equation model with the quadratic constitutive relation Reynolds stress model of Spalart ${ }^{16}$ and the Spalart-Shur rotation/curvature correction. ${ }^{17}$ Inviscid fluxes are computed using the Roe scheme. ${ }^{18}$ For second-order spatial accuracy, interface values required for Roe's scheme are reconstructed using gradients at grid nodes obtained by a least-squares technique. For the mixed prismatic/tetrahedral grids used in this study, the viscous fluxes are evaluated to second-order accuracy using a combination of edge-based and Green-Gauss gradients. In high gradient regions of the flow, limiters on these reconstructed values may be needed for stability. However, in the present computations, no limiters were required.

Time integration is accomplished by an Euler implicit backwards difference scheme with dual time stepping to achieve second-order accuracy. ${ }^{19,20}$ Rigid solutions were generated using a nondimensional time step of 1 with 6 subiterations, corresponding to a physical time step of 7.68E-5 sec or $13 \mathrm{kHz}$. Subiterations for static and dynamic aeroelastic solutions were further increased to 10 and 15 subiterations respectively.

Grid motion due to aeroelastic deformations is carried out by treating the CFD grid as a linear elastic medium with material properties based on the grid characteristics with appropriate application of the Geometric Conservation Law. ${ }^{21}$ In the present computations, the modulus of elasticity was boosted near the wing by setting it to vary with the inverse of the square of the distance away from the wing surface, thereby increasing the robustness of the grid motion.

The structural dynamics are computed internally using a linear modal method, which was implemented in FUN3D by Biedron and Thomas ${ }^{22}$ following the approach used in CAP-TSD. ${ }^{23}$ Because of the difference between the FEM and CFD surface definitions (Figure 4), a radial basis function interpolation scheme ${ }^{24}$ was implemented to smoothly interpolate the FEM modes to the CFD grid. A total of 20 mode shapes, computed using Nastran, were used in the FUN3D computations, see Figure 5.

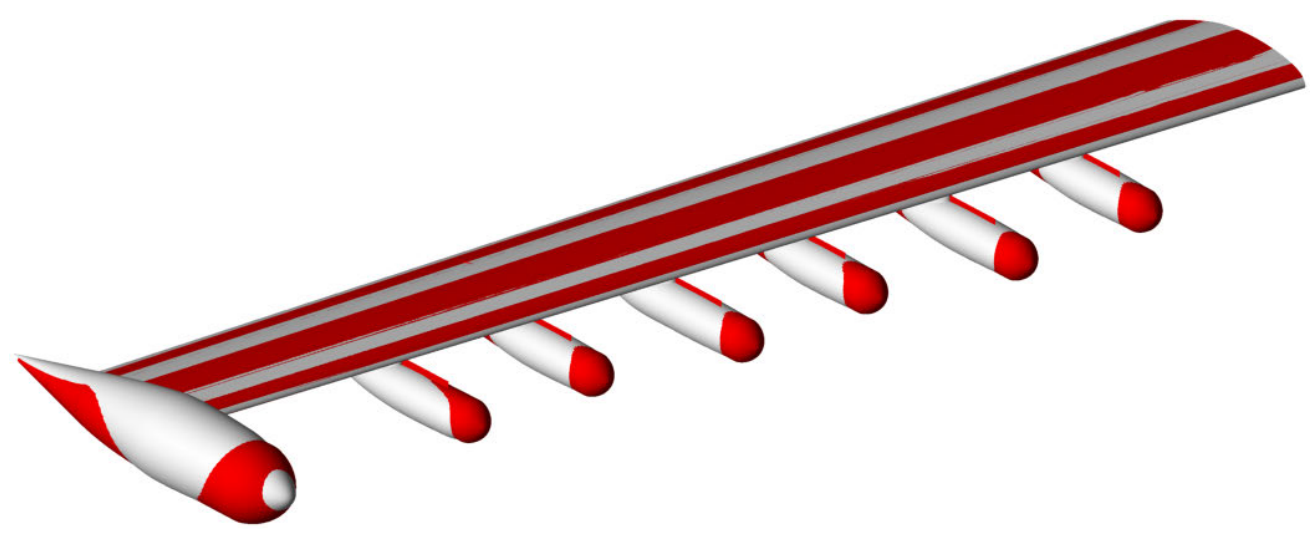

Figure 4: Surface definitions used for Nastran (red) and FUN3D (gray) overlaid. 


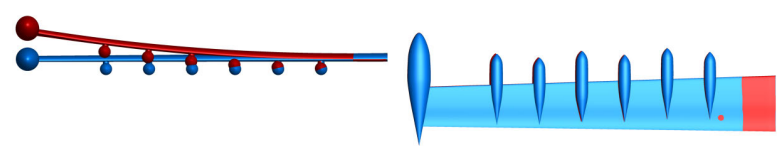

(a) Mode 1: $1.8 \mathrm{~Hz}$, wing 1st bending

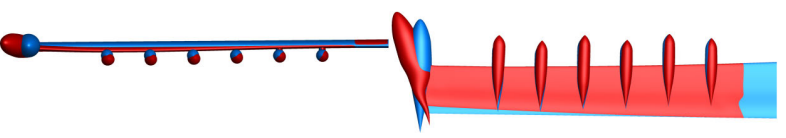

(c) Mode 3: $10.8 \mathrm{~Hz}$, tip nacelle yaw

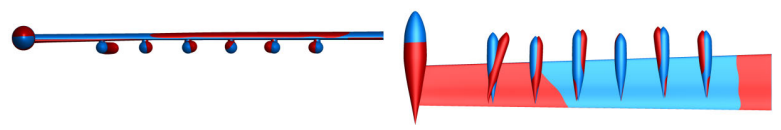

(e) Mode 5: $22.6 \mathrm{~Hz}$, high lift nacelle yaw

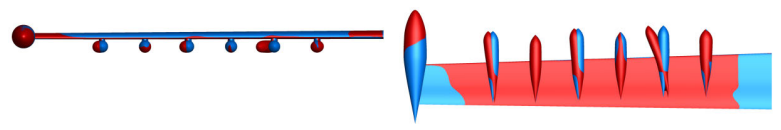

(g) Mode 7: $22.9 \mathrm{~Hz}$, high lift nacelle yaw

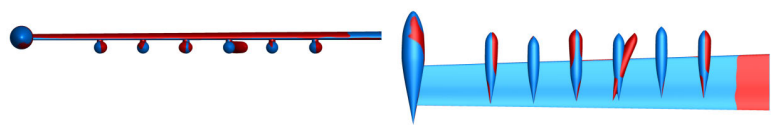

(i) Mode 9: $23.0 \mathrm{~Hz}$, high lift nacelle yaw

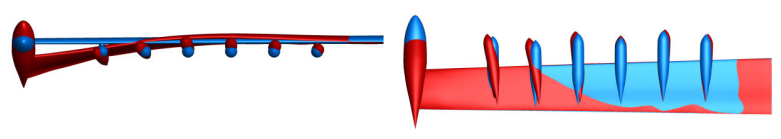

(k) Mode 11: $26.1 \mathrm{~Hz}$, wing 1st torsion, wing 2nd bending

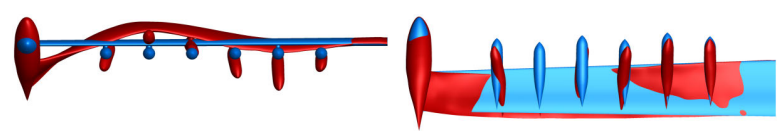

(m) Mode 13: $46.3 \mathrm{~Hz}$, high lift nacelle pitch, wing 3rd bending

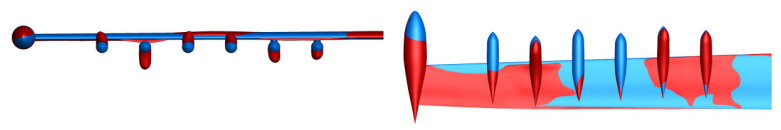

(o) Mode 15: $55.5 \mathrm{~Hz}$, high lift nacelle pitch

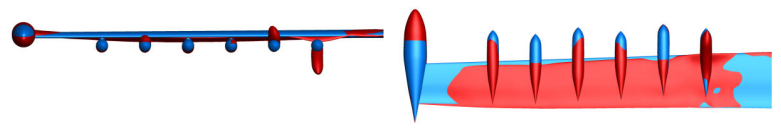

(q) Mode 17: $59.5 \mathrm{~Hz}$, high lift nacelle pitch

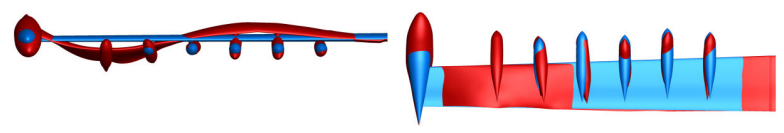

(s) Mode 19: $83.2 \mathrm{~Hz}$

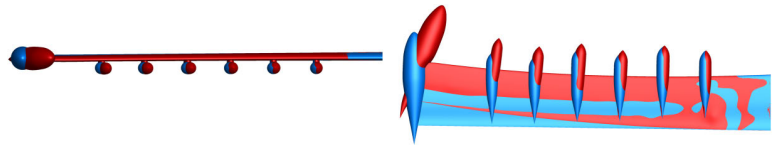

(b) Mode 2: $8.4 \mathrm{~Hz}$, wing 1st in-plane bending

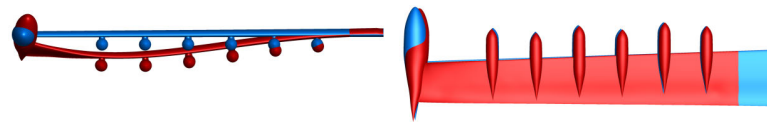

(d) Mode 4: $11.4 \mathrm{~Hz}$, wing 2nd bending, wing 1st torsion

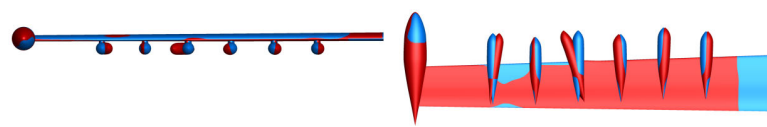

(f) Mode 6: $22.8 \mathrm{~Hz}$, high lift nacelle yaw

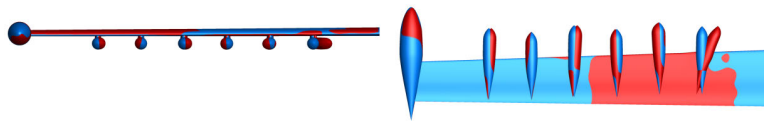

(h) Mode 8: $22.9 \mathrm{~Hz}$, high lift nacelle yaw

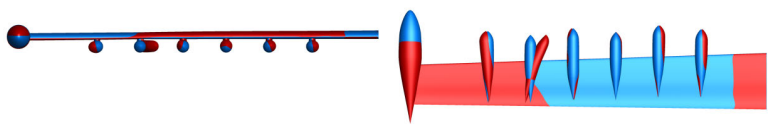

(j) Mode 10: $23.4 \mathrm{~Hz}$, high lift nacelle yaw

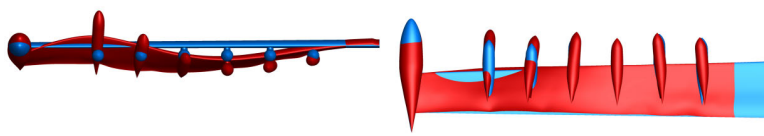

(1) Mode 12: $33.0 \mathrm{~Hz}$, high lift nacelle pitch, wing 2nd torsion

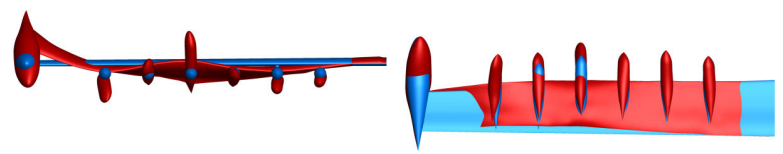

(n) Mode 14: $50.7 \mathrm{~Hz}$, high lift nacelle pitch, wing 3rd torsion

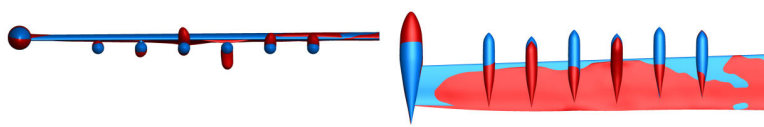

(p) Mode 16: $57.6 \mathrm{~Hz}$, high lift nacelle pitch

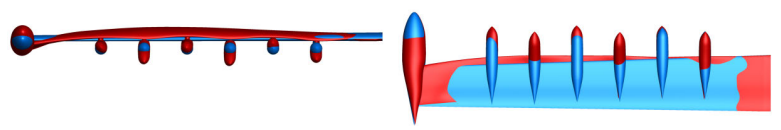

(r) Mode 18: $60.3 \mathrm{~Hz}$, high lift nacelle pitch

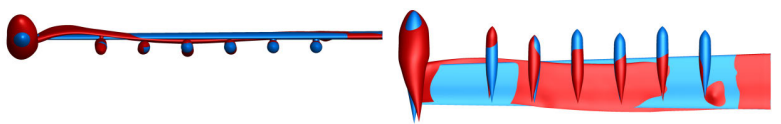

(t) Mode 20: $124.9 \mathrm{~Hz}$

Figure 5: Front and bottom views of structural mode shapes shown in red against the rigid wing shape in blue. 


\section{Results}

In the following subsections, Nastran and FUN3D results are compared for rigid wing aerodynamics, static aeroelastic loads and deflections and dynamic aeroelastic stability results. Results are presented at the nominal cruise condition and a flutter clearance condition with a dynamic pressure of over three times higher than the nominal value, see Table 1. Note, the tabulated dynamic pressure here is used to scale the aeroelastic displacements and is set independently of the freestream conditions. Hence, for the flutter clearance condition, the flow parameters were not point matched to produce a higher dynamic pressure, but rather held constant. This is standard practice, and is done so that the aerodynamics are not altered by imposing an artificially high density or Mach number.

Table 1: Analysis conditions.

\begin{tabular}{lrccccc}
\hline \hline Condition & $q_{\infty}, \mathrm{psi}$ & $M$ & $\alpha,{ }^{\circ}$ & $R e$ per in & $T,{ }^{\circ} \mathrm{R}$ & $u_{\infty}$, in $/ \mathrm{sec}$ \\
\hline Cruise & 0.559 & 0.2706 & 0.0 & $127,864.5$ & 490.14 & 3524.147 \\
Flutter Clearance & 1.748 & 0.2706 & 0.0 & $127,864.5$ & 490.14 & 3524.147 \\
\hline \hline
\end{tabular}

\section{A. Rigid}

Nastran and FUN3D computed force and pitching moment coefficients for the rigid wing at the cruise condition are shown in Table 2 along with the center of pressure. The percent error in lift, drag and pitching moment coefficients relative to the ultra fine grid are shown in Table 3. The incremental error between the family of CFD meshes is less than $1 \%$ and the trend among all meshes is monotonic with respect to node count, with the exception of the drag prediction on the medium grid, whose error rose by $0.9 \%$. Compared to FUN3D, Nastran overpredicts lift by $13.7 \%$. Drag could not be computed with the doublet lattice methodology, resulting in the error value of $100 \%$ in drag coefficient. The pitching moment from Nastran is seen to be a $43 \%$ greater in magnitude and opposite in sign to the ultra fine FUN3D prediction. This mismatch is reflected in the location of the center of pressure, which for the Nastran result is $5 \% \mathrm{c}$ ahead of the wing leading edge, while the FUN3D solutions are consistently at $49 \% \mathrm{c}$. The $\Delta C_{p}$ from Nastran, computed by subtracting the top surface $C_{p}$ from the bottom surface $C_{p}$ (for the CFD solutions), is lower than FUN3D for the first $75 \%$ chord and larger on the last $25 \%$ chord, Figure 6 . This distribution is the cause of the difference observed in pitching moment. Discontinuities in $\Delta C_{p}$ on the wing in the FUN3D plot are due to the pylons, which were modeled as vertical flat plates aerodynamically in Nastran.

Table 2: Rigid: Force, pitching moment, and center of pressure. ${ }^{a}$

\begin{tabular}{|c|c|c|c|c|c|c|}
\hline Case & Grid $\mathrm{N}$ & Nodes & $C_{L}$ & $C_{D}$ & $C_{m}$ & $\bar{x}_{c p}$ \\
\hline Nastran & $55 \mathrm{~K}^{\mathrm{b}}$ & $6.7 \mathrm{~K}^{\mathrm{c}}$ & 0.832 & 0 & 0.249 & -0.0497 \\
\hline FUN3D Tiny & & $6.7 \mathrm{M}$ & 0.757 & 0.03212 & -0.182 & 0.4903 \\
\hline FUN3D Coarse & & $9.1 \mathrm{M}$ & 0.754 & 0.03207 & -0.181 & 0.4899 \\
\hline FUN3D Medium & & $12.9 \mathrm{M}$ & 0.749 & 0.03236 & -0.179 & 0.4888 \\
\hline FUN3D Ultra Fine & & 31.9M & 0.732 & 0.03157 & -0.174 & 0.4883 \\
\hline
\end{tabular}

Differences in surface pressure between each grid relative to the ultra fine grid are shown on the right hand side of Figures 7 and 8 . The upper wing surfaces show excellent convergence with most surfaces having an absolute difference in $C_{p}$ on the order of $1 \%$ of its full value. In the set of bottom views in Figure 8, differences in the separated flow at the pylon wing junctions are evident for all meshes. For the present RANS computations, the separated flow regions do not impart any significant unsteady loads. To resolve the true unsteadiness due to flow separation would require a higher fidelity turbulence model, such as delayed detached eddy simulation. However, it is expected that further refinements in the OML in this region will mitigate the separated flow. 
Table 3: Rigid: Percent error in force and pitching moment coefficients with respect to ultra fine grid.

\begin{tabular}{lrrrrr}
\hline \hline & & \multicolumn{4}{c}{ Percent Error (\%) } \\
Case & \multicolumn{2}{c}{ Grid Nodes } & $C_{L}$ & \multicolumn{1}{c}{$C_{D}$} & $C_{m}$ \\
\hline Nastran & \multirow{2}{*}{$55 \mathrm{~K}^{\mathrm{b}}}$, & $6.7 \mathrm{~K}^{\mathrm{c}}$ & -13.7 & 100.0 & 243.0 \\
FUN3D Tiny & & $6.7 \mathrm{M}$ & -3.5 & -1.7 & -4.4 \\
FUN3D Coarse & $9.1 \mathrm{M}$ & -3.0 & -1.6 & -3.7 \\
FUN3D Medium & $12.9 \mathrm{M}$ & -2.3 & -2.5 & -2.6 \\
\hline \hline
\end{tabular}

${ }^{\text {a }}$ Percent error defined here as (Ultra Fine - Current)/Ultra Fine $\times 100 \%$

${ }^{\mathrm{b}}$ Structural elements.

${ }^{\mathrm{c}}$ Aerodynamic panels.

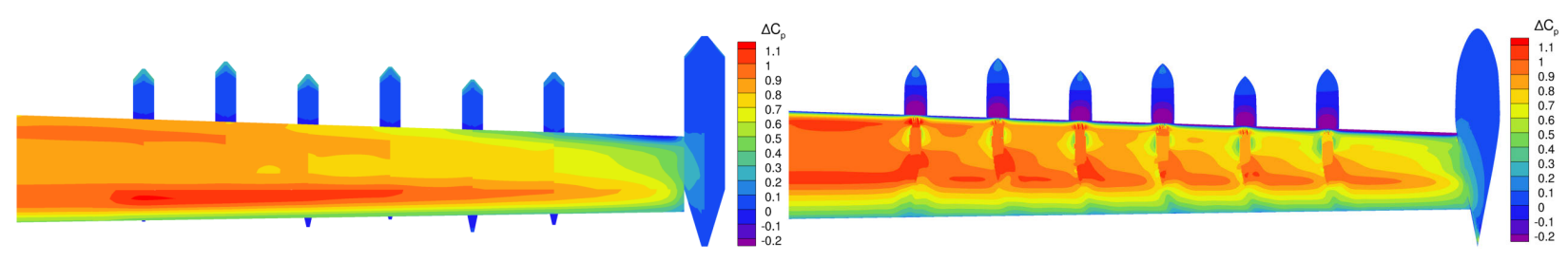

(a) Rigid: Nastran

(b) Rigid: FUN3D

Figure 6: $C_{p}$ (lower surface)- $C_{p}$ (upper surface) shown on Nastran and FUN3D aerodynamic surfaces. 


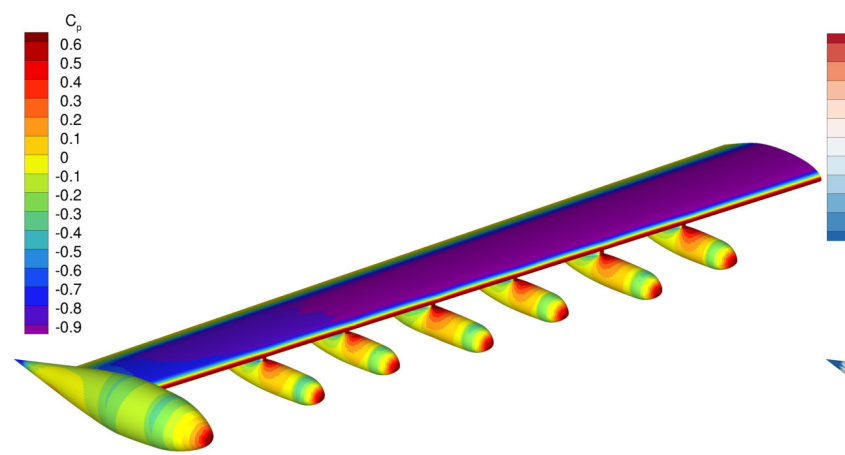

(a) tiny $C_{p}$

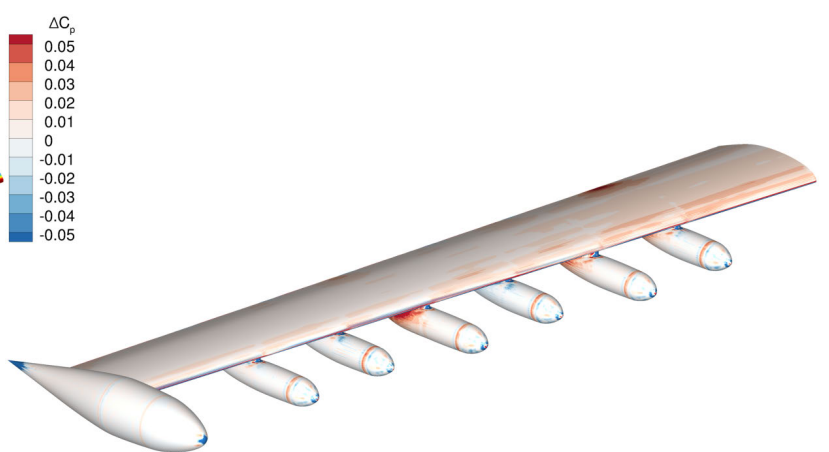

(b) tiny $\Delta C_{p}$

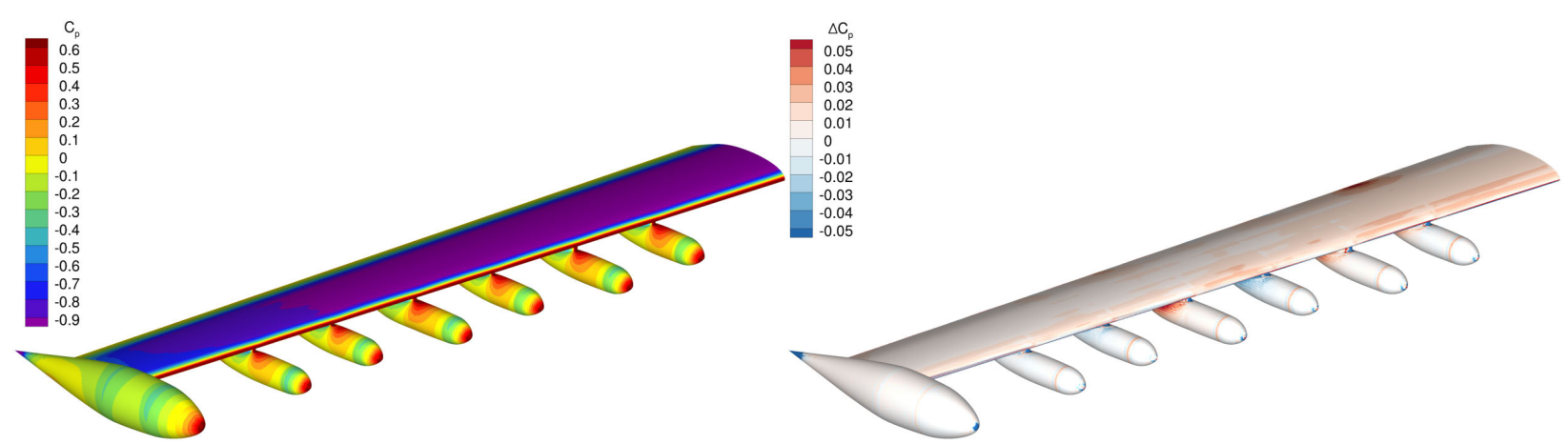

(c) coarse $C_{p}$

(d) coarse $\Delta C_{p}$

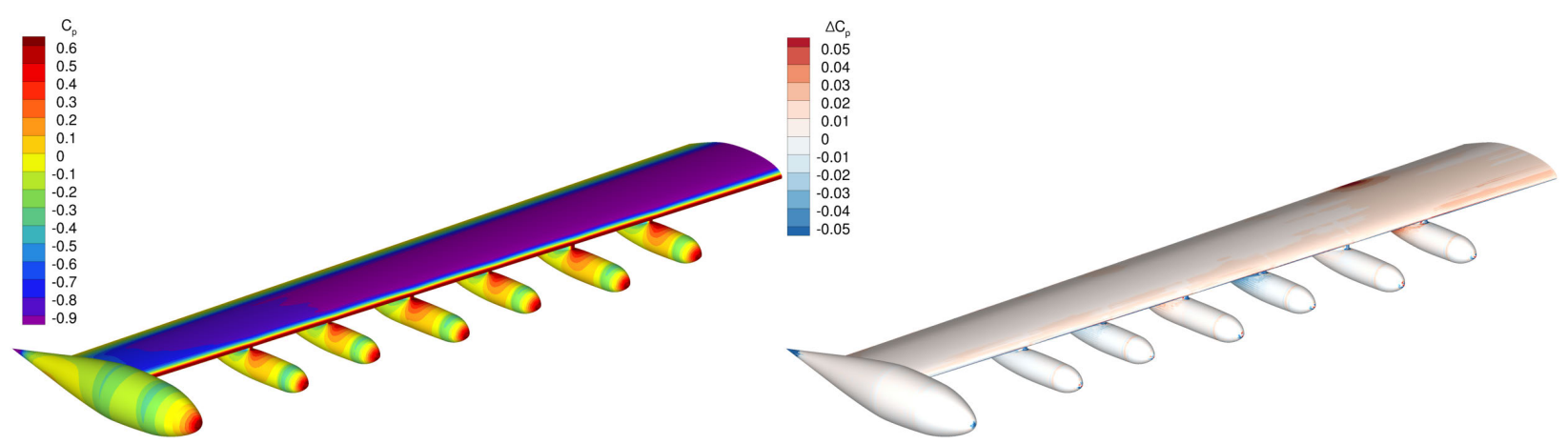

(e) medium $C_{p}$

(f) medium $\Delta C_{p}$

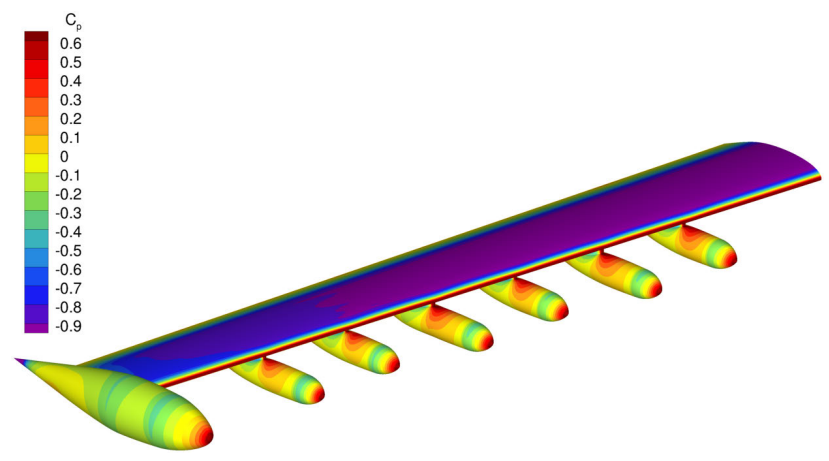

(g) ultra fine $C_{p}$

Figure 7: Rigid: top surface pressure grid convergence. 


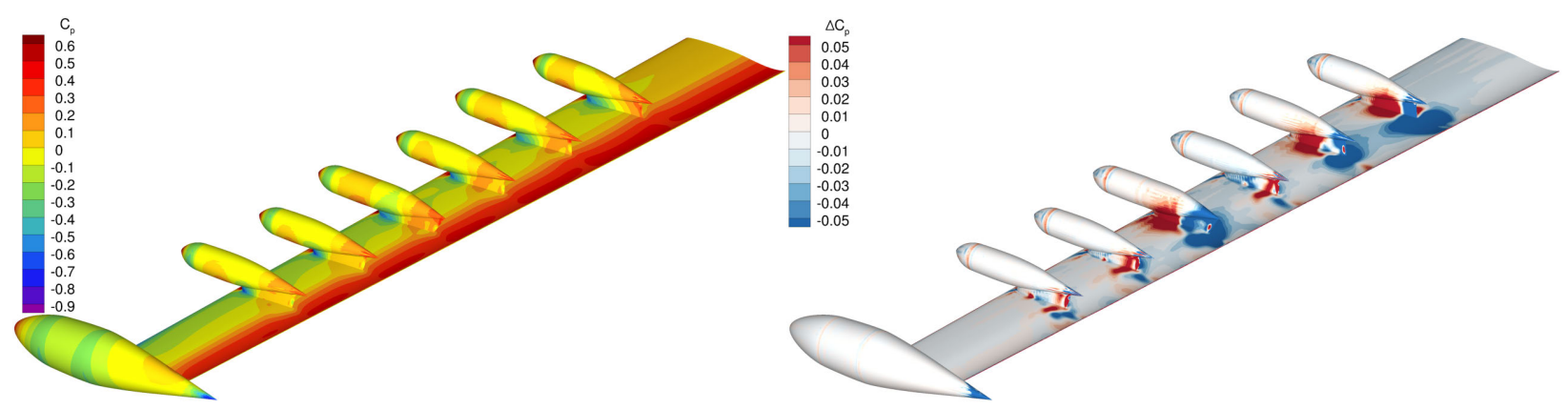

(a) tiny $C_{p}$

(b) tiny $\Delta C_{p}$

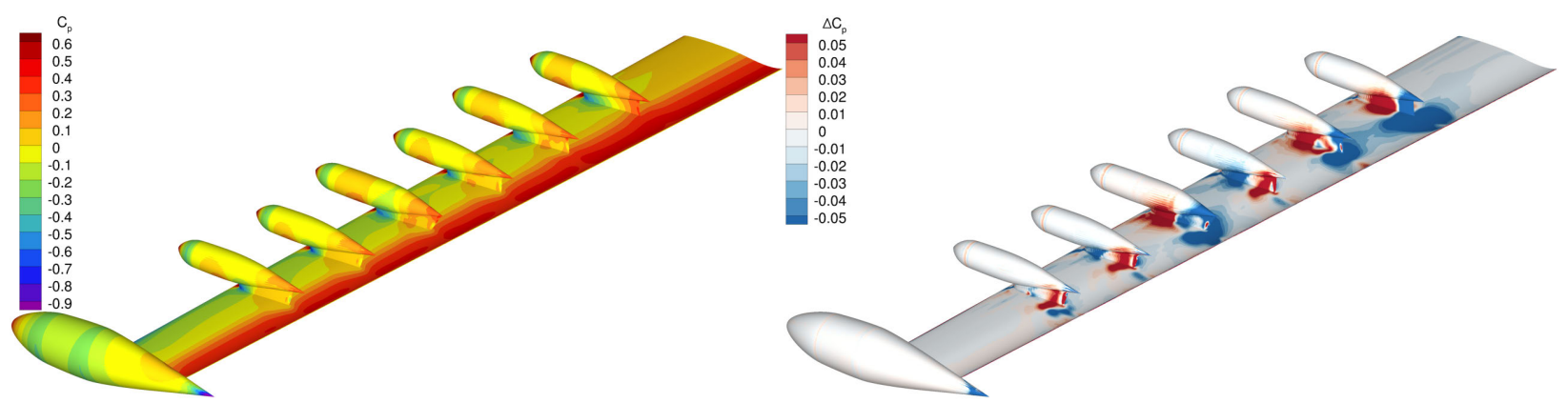

(c) coarse $C_{p}$

(d) coarse $\Delta C_{p}$

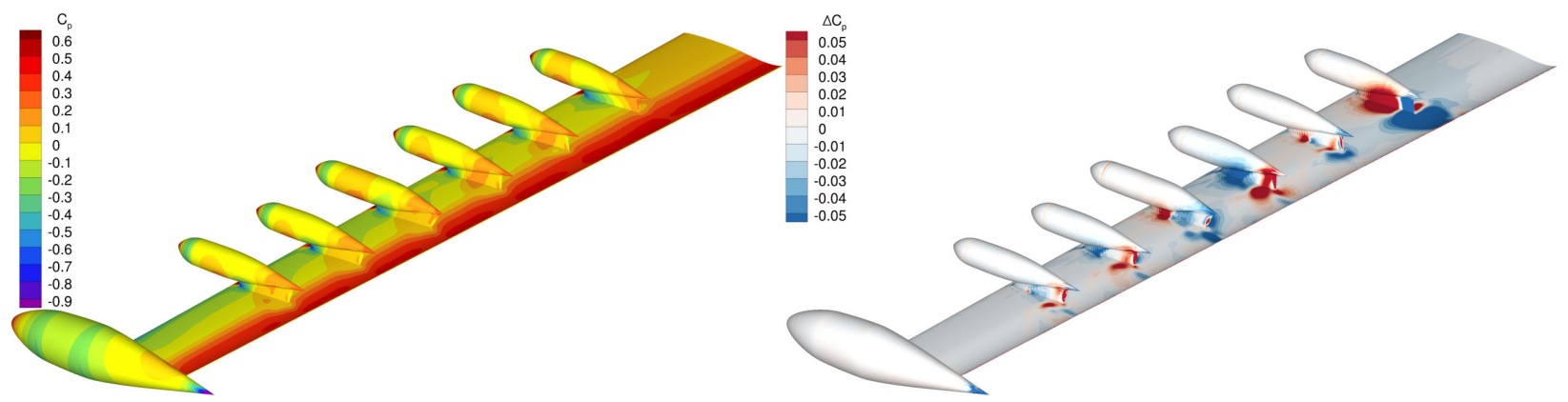

(e) medium $C_{p}$

(f) medium $\Delta C_{p}$

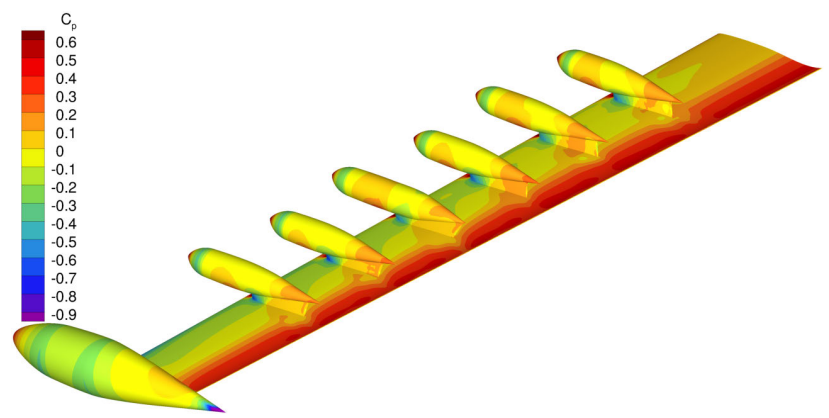

(g) ultra fine $C_{p}$

Figure 8: Rigid: bottom surface pressure grid convergence. 


\section{B. Static Aeroelastic}

Static aeroelastic computations were performed at the cruise and flutter clearance dynamic pressures, see Table 1. Force and pitching moment coefficients at the cruise condition (Table 4) along with the corresponding percent errors (Table 5) follow the same trend as the rigid results. This is also true for the flutter clearance dynamic pressure results shown in Tables 6 and 7.

Table 4: Static Aeroelastic $q=0.559$ psi: Force, pitching moment, and center of pressure. $^{\mathbf{a}}$

\begin{tabular}{lrrrrrr}
\hline \hline Case & \multicolumn{2}{c}{ Grid Nodes } & $C_{L}$ & $C_{D}$ & $C_{m}$ & $\bar{x}_{c p}$ \\
\hline Nastran & $55 \mathrm{~K}^{\mathrm{b}}$, & $6.7 \mathrm{~K}^{\mathrm{c}}$ & 0.849 & 0 & 0.258 & -0.0538 \\
FUN3D Tiny & & $6.7 \mathrm{M}$ & 0.770 & 0.03284 & -0.176 & 0.4787 \\
FUN3D Coarse & $9.1 \mathrm{M}$ & 0.772 & 0.03259 & -0.176 & 0.4785 \\
FUN3D Medium & $12.9 \mathrm{M}$ & 0.768 & 0.03288 & -0.175 & 0.4774 \\
FUN3D Ultra Fine & $31.9 \mathrm{M}$ & 0.750 & 0.03214 & -0.170 & 0.4770 \\
\hline \hline & \multirow{2}{*}{ a Reference area $=4800$ in $^{2}$, Reference chord $=25.56$ in, Moment center $(1 / 4 \mathrm{c})=(131.503}$, \\
$\quad$ 0.0, 35.613) in. \\
b Structural elements. \\
c Aerodynamic panels.
\end{tabular}

Table 5: Static Aeroelastic $q=0.559$ psi: Percent error in force and pitching moment coefficients with respect to ultra fine grid.

\begin{tabular}{lrrrrr}
\hline \hline & & \multicolumn{4}{c}{ Percent Error (\%) } \\
Case & Grid Nodes & \multicolumn{1}{c}{$C_{L}$} & \multicolumn{1}{c}{$C_{D}$} & \multicolumn{1}{c}{$C_{m}$} \\
\hline Nastran & $55 \mathrm{~K}^{\mathrm{b}}$ & $6.7 \mathrm{~K}^{\mathrm{c}}$ & -13.3 & 100.0 & 251.6 \\
FUN3D Tiny & & $6.7 \mathrm{M}$ & -2.7 & -2.2 & -3.5 \\
FUN3D Coarse & $9.1 \mathrm{M}$ & -3.0 & -1.4 & -3.7 \\
FUN3D Medium & $12.9 \mathrm{M}$ & -2.4 & -2.3 & -2.6 \\
\hline \hline
\end{tabular}

${ }^{a}$ Percent error defined here as (Ultra Fine - Current)/Ultra Fine $\times 100 \%$

${ }^{\mathrm{b}}$ Structural elements.

${ }^{\mathrm{c}}$ Aerodynamic panels.

The percent change in force and pitching moment coefficients from rigid to static aeroelastic deflection for cruise and flutter clearance conditions are shown in Tables 8 and 9, respectively. Though the absolute values of forces and moments (Tables 2-7) show more variation between Nastran and among the grid levels in FUN3D, the static increments are remarkably similar with the exception of pitching moment. As with the rigid results, the pitching moment from Nastran is seen to be a much greater in magnitude and opposite in sign to the ultra fine FUN3D prediction. This mismatch is reflected in the location of the center of pressure, which for the Nastran result is about $5 \% \mathrm{c}$ ahead of the wing leading edge, while the FUN3D solutions are near the midchord. With increasing dynamic pressure, the center of pressure is seen to move forward for both Nastran and FUN3D results. $\Delta C_{p}$, computed by subtracting the top surface value from the bottom, shown in Figure 9, shows a similar distribution to the rigid case (Figure 6), with overall higher values due to larger deflections. Despite the differences in loads between Nastran and FUN3D, the final deflections are very similar with vertical tip displacements of 9.4 and 9.9 inches, respectively, at the cruise dynamic pressure (Figure 10) and 32.3 and 35.5 inches for Nastran and FUN3D, respectively, for the higher dynamic pressure case. It is worth noting that Nastran computations that include inertial forces (self-weight), result in wing deformations of about 4 inches less, due to inertial relief. 


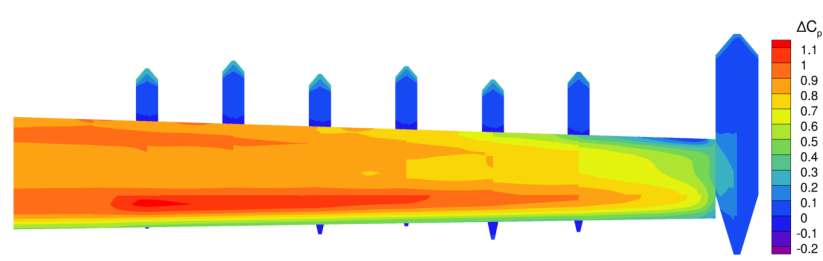

(a) Static aeroelastic $q=0.559$ psi: Nastran

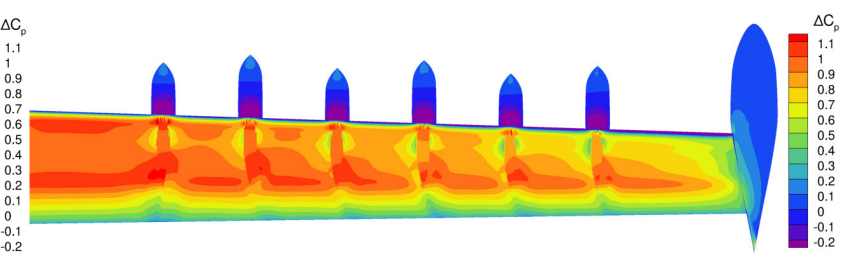

(b) Static aeroelastic $q=0.559$ psi: FUN3D

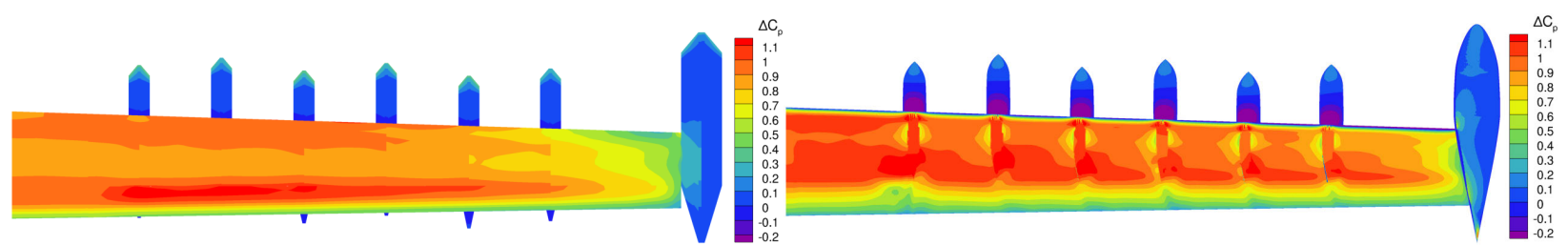

(c) Static aeroelastic $q=1.748$ psi: Nastran

(d) Static aeroelastic $q=1.748$ psi: FUN3D

Figure 9: $C_{p}$ (lower surface)- $C_{p}$ (upper surface) shown on Nastran and FUN3D aerodynamic surfaces.

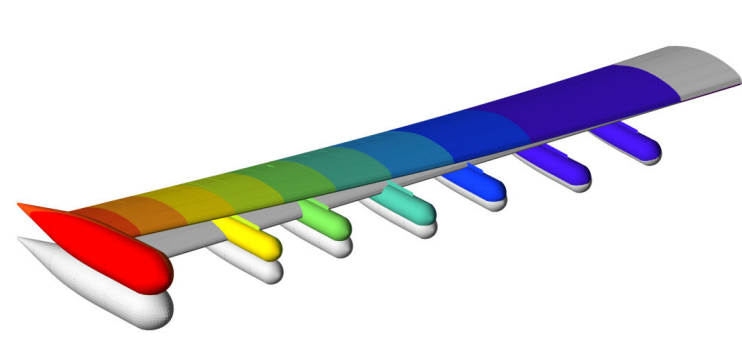

(a) $q=0.559$ psi: Nastran

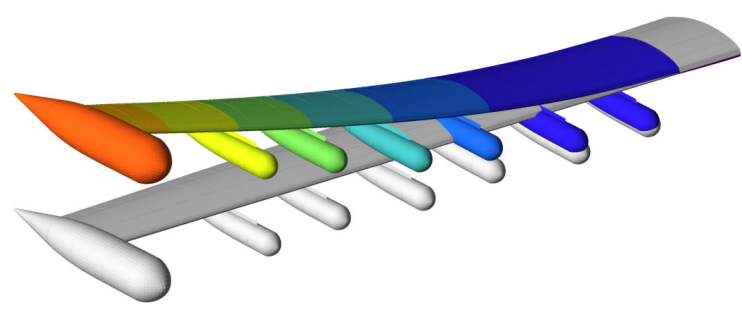

(c) $q=1.748$ psi: Nastran

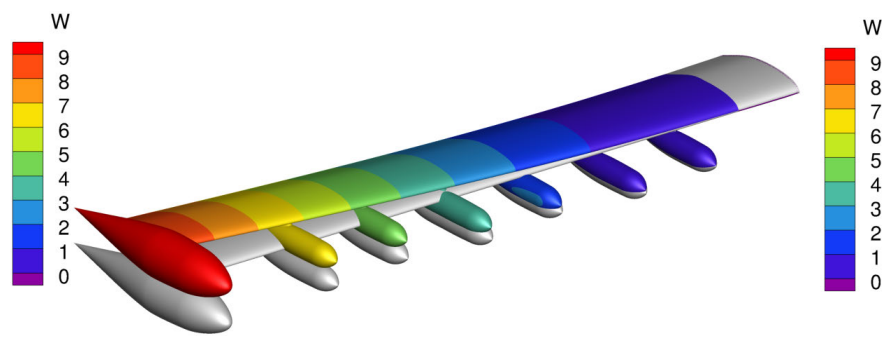

(b) $q=0.559$ psi: FUN3D

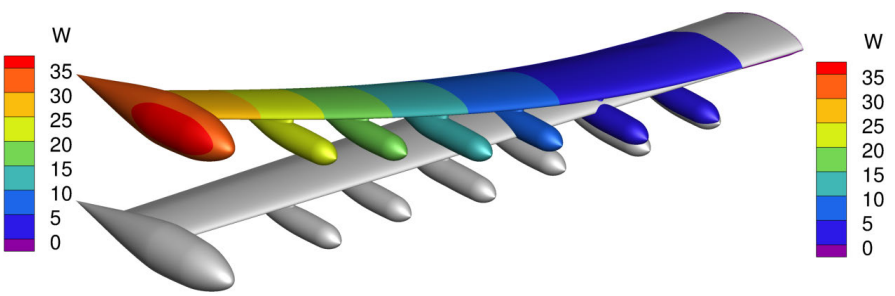

(d) $q=1.748$ psi: FUN3D

Figure 10: Static aeroelastic position colored by vertical displacement in inches. Rigid wing surface shown in gray. 
Table 6: Static Aeroelastic $q=1.748$ psi: Force, pitching moment, and center of pressure. $^{\text {a }}$

\begin{tabular}{|c|c|c|c|c|c|c|}
\hline Case & Grid I & Nodes & $C_{L}$ & $C_{D}$ & $C_{m}$ & $\bar{x}_{c p}$ \\
\hline Nastran & $55 \mathrm{~K}^{\mathrm{b}}$ & $6.7 \mathrm{~K}^{\mathrm{c}}$ & 0.898 & 0 & 0.281 & -0.0628 \\
\hline FUN3D Tiny & & $6.7 \mathrm{M}$ & 0.837 & 0.03584 & -0.164 & 0.4458 \\
\hline FUN3D Coarse & & $9.1 \mathrm{M}$ & 0.841 & 0.03535 & -0.165 & 0.4461 \\
\hline FUN3D Medium & & $12.9 \mathrm{M}$ & 0.834 & 0.03577 & -0.162 & 0.4445 \\
\hline FUN3D Ultra Fine & & $31.9 \mathrm{M}$ & 0.816 & 0.03493 & -0.159 & 0.4451 \\
\hline
\end{tabular}

Table 7: Static Aeroelastic $q=1.748$ psi: Percent error in force and pitching moment coefficients with respect to ultra fine grid.

\begin{tabular}{lrrrrr}
\hline \hline & & \multicolumn{4}{c}{ Percent Error $(\%)^{\mathrm{a}}$} \\
Case & Grid Nodes & \multicolumn{1}{c}{$C_{L}$} & $C_{D}$ & $C_{m}$ \\
\hline Nastran & $55 \mathrm{~K}^{\mathrm{b}}$, & $6.7 \mathrm{~K}^{\mathrm{c}}$ & -10.1 & 100.0 & 276.6 \\
FUN3D Tiny & & $6.7 \mathrm{M}$ & -2.7 & -2.6 & -3.0 \\
FUN3D Coarse & $9.1 \mathrm{M}$ & -3.1 & -1.2 & -3.6 \\
FUN3D Medium & $12.9 \mathrm{M}$ & -2.3 & -2.4 & -2.0 \\
\hline \hline
\end{tabular}

${ }^{\text {a }}$ Percent error defined here as (Ultra Fine - Current)/Ultra Fine $\times 100 \%$

${ }^{\mathrm{b}}$ Structural elements.

${ }^{\mathrm{c}}$ Aerodynamic panels.

\section{Dynamic Aeroelastic}

A Nastran flutter analysis was performed to determine the flutter dynamic pressure, see Figure 11. It was found that no oscillatory instability existed, only that of divergence, which occurred in the first bending mode at 5.931 psi. FUN3D analysis at this dynamic pressure confirmed the divergence instability. Because the pressure was so much higher than the flutter clearance limit of $1.748 \mathrm{psi}$, no attempt was made to locate the precise onset value predicted by FUN3D. Comparisons were made at the flutter clearance point and are shown in the root locus diagram of Figure 12 for the first four modes. Computing the root locus from the time domain data of CFD is sensitive to the length of the record as well as the system identification process used, which in the present study was a filtered log decrement approach. Future analyses will use Silva et al.' $\mathrm{s}^{25}$ computationally efficient FUN3D-based reduced-order modeling to generate root locus data.

The overall stability is confirmed by examining the grid converged tip displacement and rotation history (Figure 13), which is very clearly damped. Excellent grid convergence is also seen in the modal response history at the flutter clearance dynamic pressure for each of the four grids in Figure 14. The response plots contain the static aeroelastic solution phase where structural damping was set to a high value (shown from 0 to 1.5 seconds) and the subsequent dynamic response where structural damping was set to 0 (shown from 1.5 to 3.5 seconds). In an effort to avoid a prolonged response time by overexciting modes that would in reality not be very active, the magnitude of this excitation was based on the maximum observed modal velocity during the static aeroelastic phase. This original excitation method (type 1) worked well for modes that were very active, such as first bending and first torsion modes. However, for modes that were not active, like the high lift nacelles, this modal excitation approach resulted in very small excitations that appeared to be unstable, when in reality they were just exceedingly small oscillations on their way to developing into very small lightly damped oscillations. 
Table 8: $q=0.559$ psi: Percent change in force and pitching moment coefficients from rigid to static aeroelastic deflection.

\begin{tabular}{lccccr}
\hline \hline & & \multicolumn{4}{c}{ Percent Change (\%) } \\
Case & Grid Nodes & $C_{L}$ & $C_{D}$ & $C_{m}$ \\
\hline Nastran & $55 K^{\mathrm{b}}$, & $6.7 \mathrm{~K}^{\mathrm{c}}$ & 2.1 & NA & 3.5 \\
FUN3D Tiny & & $6.7 \mathrm{M}$ & 1.7 & 2.3 & -3.3 \\
FUN3D Coarse & & $9.1 \mathrm{M}$ & 2.5 & 1.6 & -2.4 \\
FUN3D Medium & $12.9 \mathrm{M}$ & 2.5 & 1.6 & -2.3 \\
FUN3D Ultra Fine & & $31.9 \mathrm{M}$ & 2.5 & 1.8 & -2.4 \\
\hline \hline
\end{tabular}

${ }^{a}$ Percent change defined here as (aeroelastic - rigid) $/$ rigid $\times 100 \%$

Table 9: $q=1.748$ psi: Percent change in force and pitching moment coefficients from rigid to static aeroelastic deflection.

\begin{tabular}{lrrrrr}
\hline \hline & & \multicolumn{4}{c}{ Percent Change (\%) } \\
Case & Grid Nodes & \multicolumn{1}{c}{$C_{L}$} & \multicolumn{1}{c}{$C_{D}$} & $C_{m}$ \\
\hline Nastran & $55 K^{\mathrm{b}}$, & $6.7 \mathrm{~K}^{\mathrm{c}}$ & 8.0 & NA & 12.7 \\
FUN3D Tiny & & $6.7 \mathrm{M}$ & 10.6 & 11.6 & -9.9 \\
FUN3D Coarse & $9.1 \mathrm{M}$ & 11.6 & 10.2 & -8.8 \\
FUN3D Medium & $12.9 \mathrm{M}$ & 11.4 & 10.5 & -9.2 \\
FUN3D Ultra Fine & $31.9 \mathrm{M}$ & 11.5 & 10.6 & -8.7 \\
\hline \hline
\end{tabular}

${ }^{\text {a }}$ Percent change defined here as (aeroelastic - rigid) /rigid $\times 100 \%$

To more clearly demonstrate the stability of each mode, another method (type 2) for modal excitation was developed to produce more physically significant physical displacements in each mode. This was accomplished by solving the modal structural equations outside of FUN3D, in an air off mode, to determine the generalized velocity perturbation required to produce a maximum deflection of five inches on a per mode basis. The results of this new modal excitation method are shown in the dashed red line and compared to the original scheme shown in black in Figure 15. From this figure, it is clear that for all modes except the first, the original excitation was much smaller than the second scheme and much more clearly damped. While a five inch deflection is fairly small compared to the wing semispan of 190 inches, it is very significant for the much stiffer high lift nacelle modes, whose maximum diameter is on the order of 6.5 inches. Another possible scheme would be to scale the maximum perturbation deflection independently for each mode by its stiffness. This will be evaluated in a future study. 

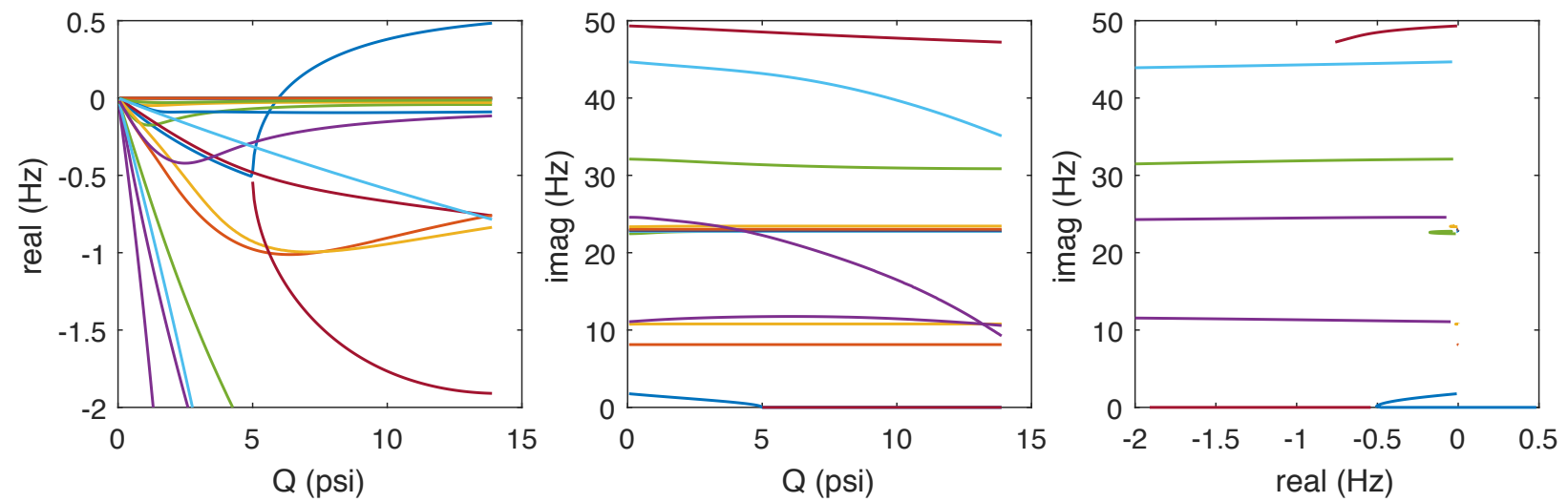

Figure 11: Nastran flutter analysis plots.

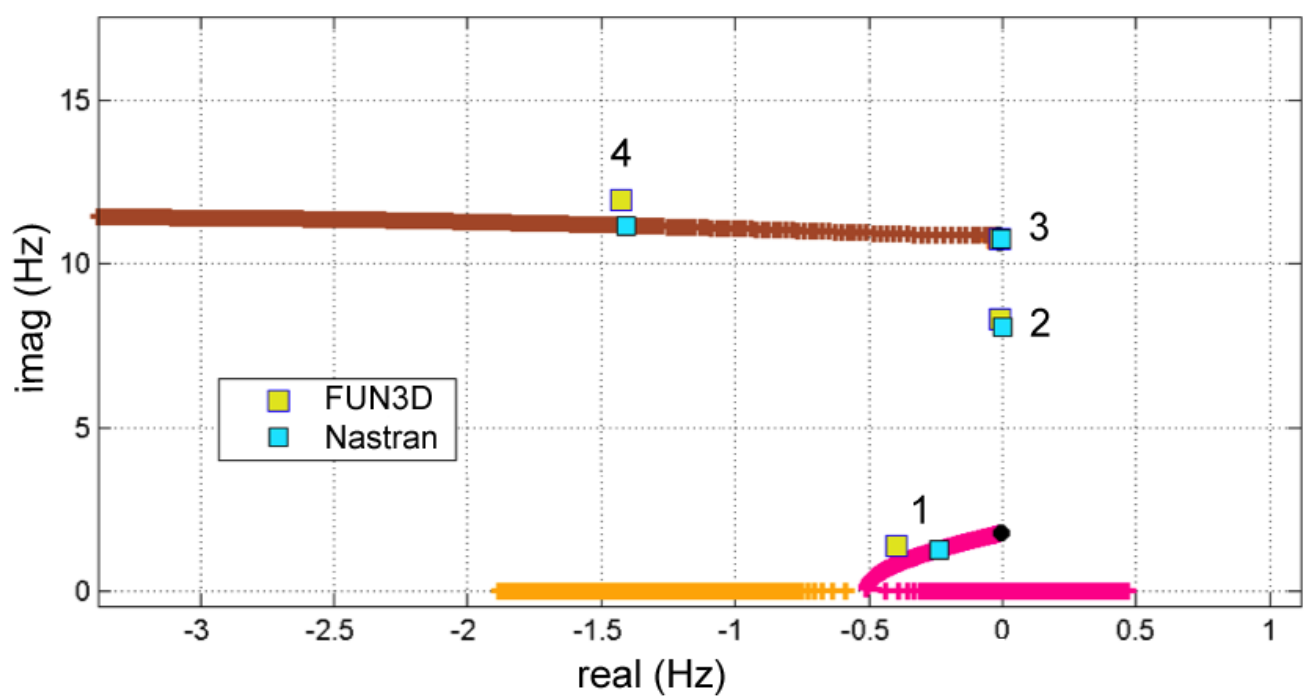

Figure 12: Comparison of root locus results from Nastran and FUN3D for first four modes at $q=1.748$ psi. Nastran results for varying dynamic pressure shown by "+" symbols. 


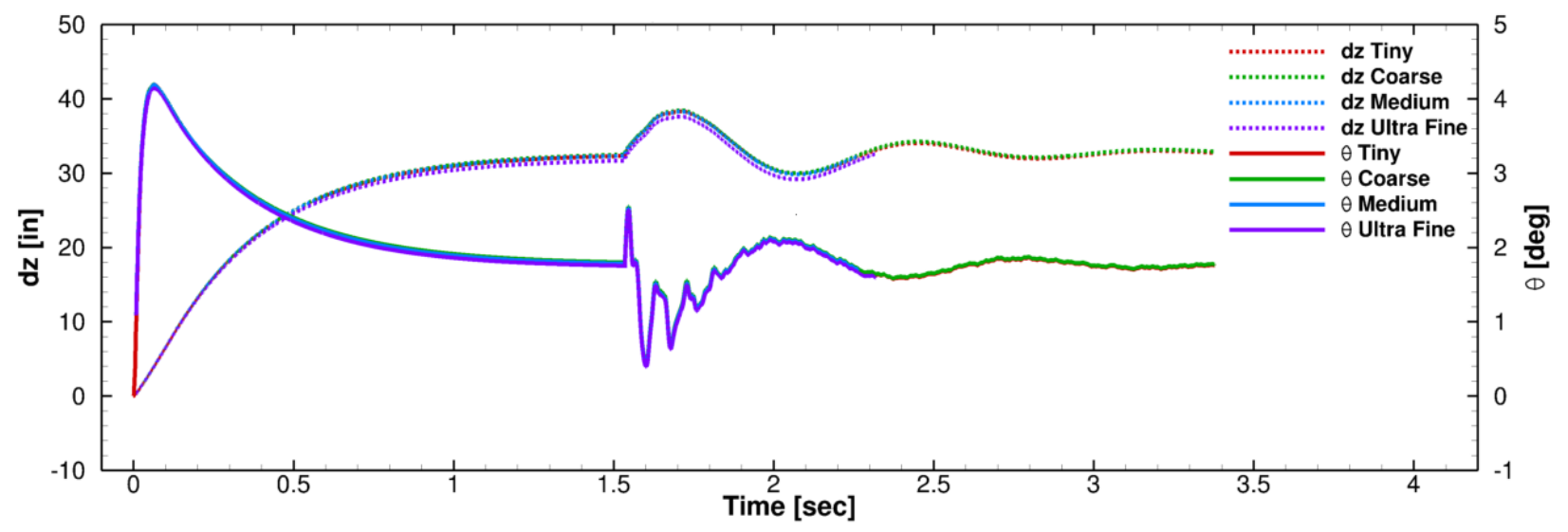

(a) Tip deflection and rotation.

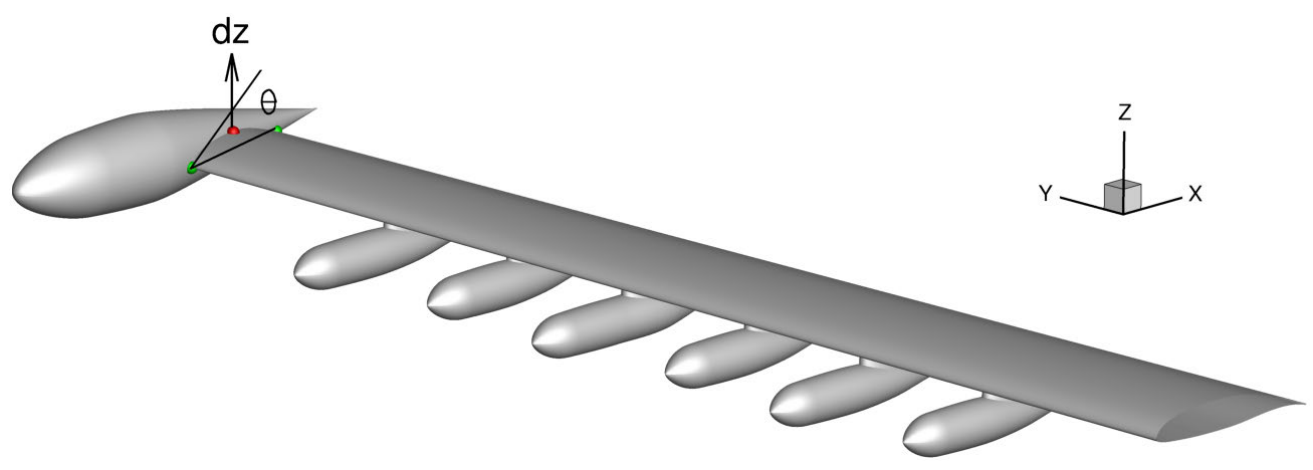

(b) $d z$ and $\theta$ orientation view.

Figure 13: $q=1.748$ psi: Grid convergence of wingtip aeroelastic response. 


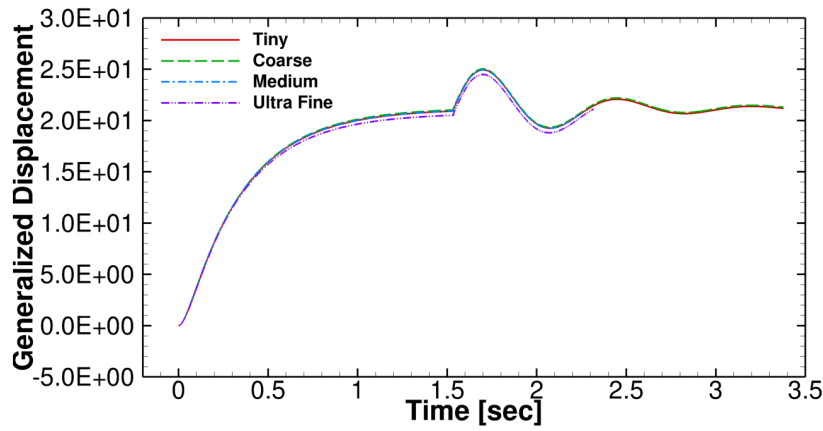

(a) Mode 1: $1.8 \mathrm{~Hz}$, wing 1st bending

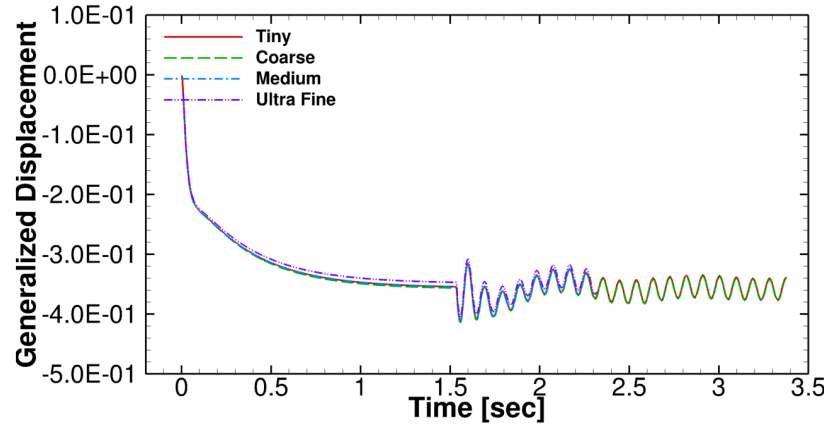

(c) Mode 3: $10.8 \mathrm{~Hz}$, tip nacelle yaw

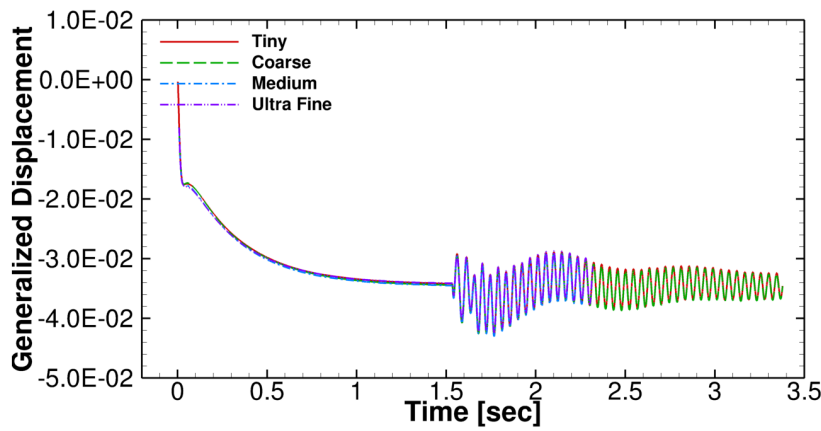

(e) Mode 5: $22.6 \mathrm{~Hz}$, high lift nacelle yaw

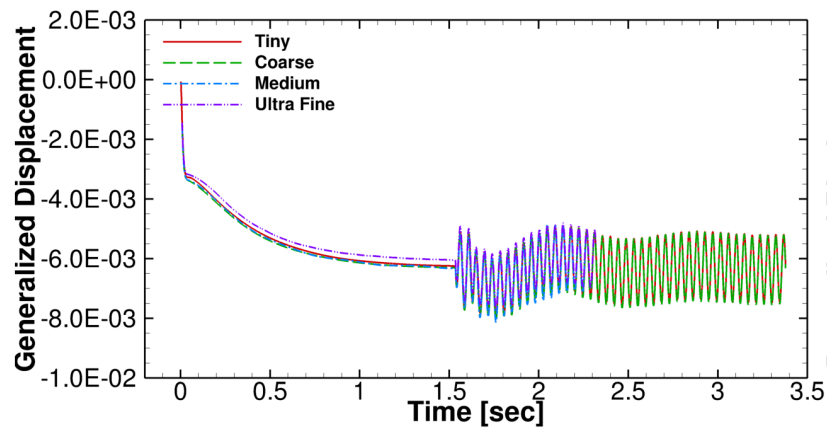

(g) Mode 7: $22.9 \mathrm{~Hz}$, high lift nacelle yaw

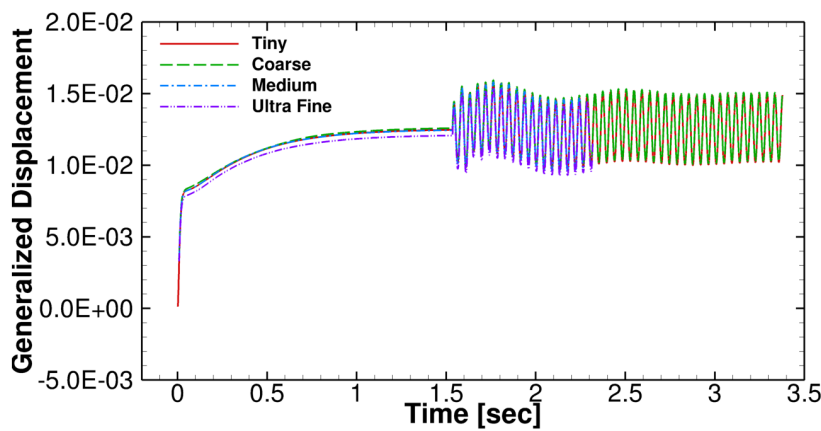

(i) Mode 9: $23.0 \mathrm{~Hz}$, high lift nacelle yaw

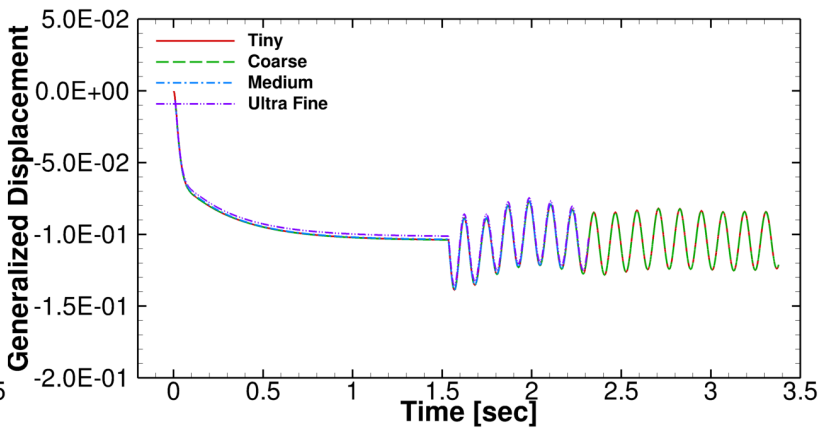

(b) Mode 2: $8.4 \mathrm{~Hz}$, wing 1st in-plane bending

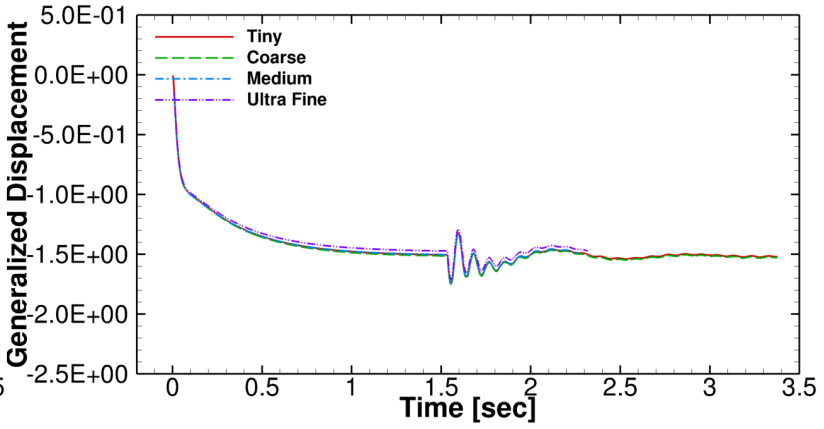

(d) Mode 4: $11.4 \mathrm{~Hz}$, wing 2nd bending, wing 1st torsion

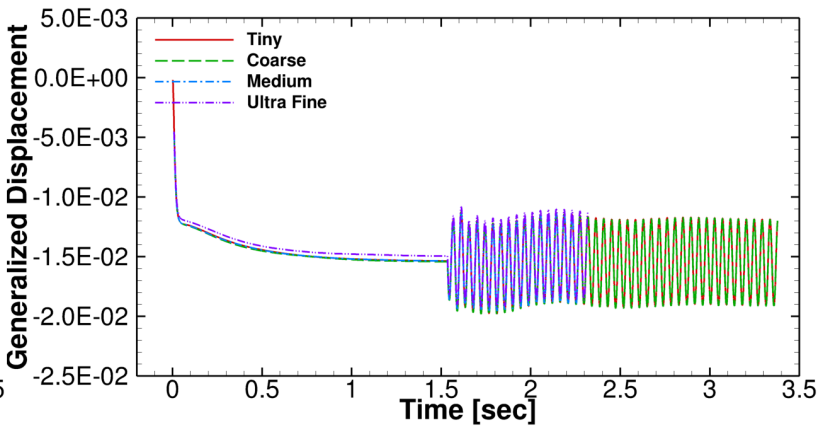

(f) Mode 6: $22.8 \mathrm{~Hz}$, high lift nacelle yaw

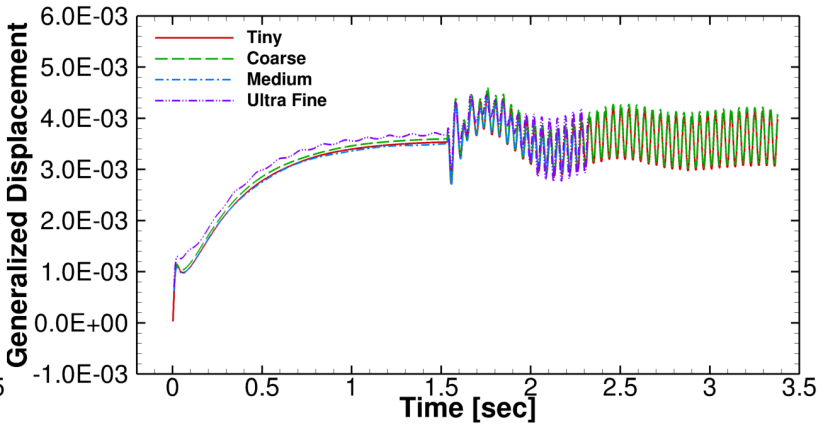

(h) Mode 8: $22.9 \mathrm{~Hz}$, high lift nacelle yaw

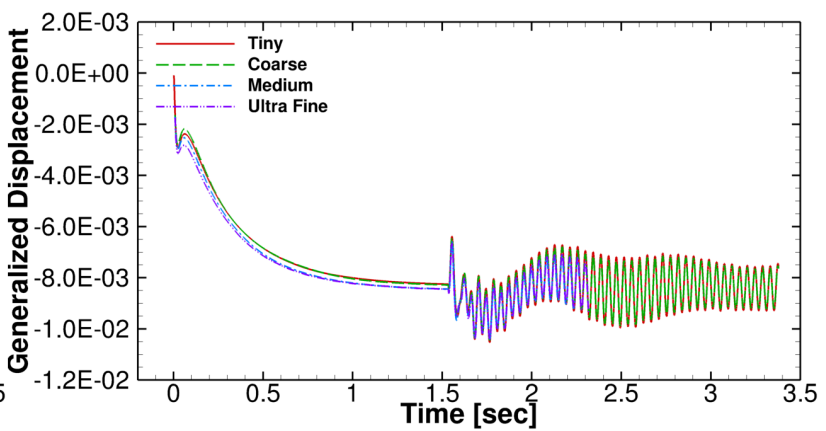

(j) Mode 10: $23.4 \mathrm{~Hz}$, high lift nacelle yaw

Figure 14: $q=1.748$ psi: Grid convergence of static and dynamic modal response for perturbation type 1 .

16 of 20 


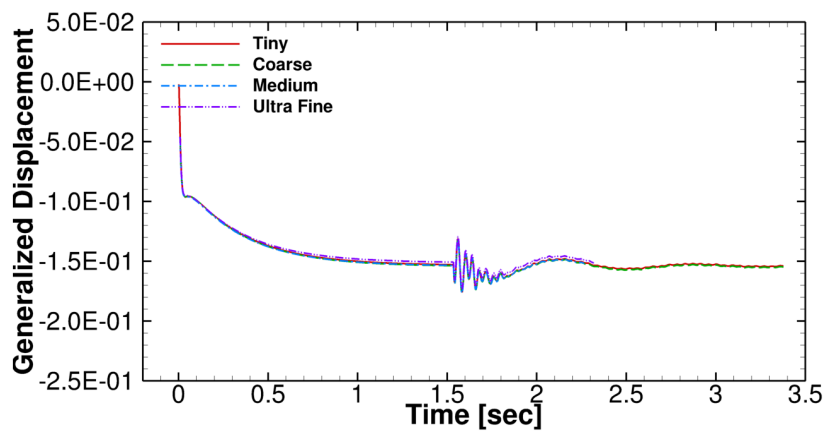

(a) Mode 11: $26.1 \mathrm{~Hz}$, wing 1st torsion, wing 2nd bending

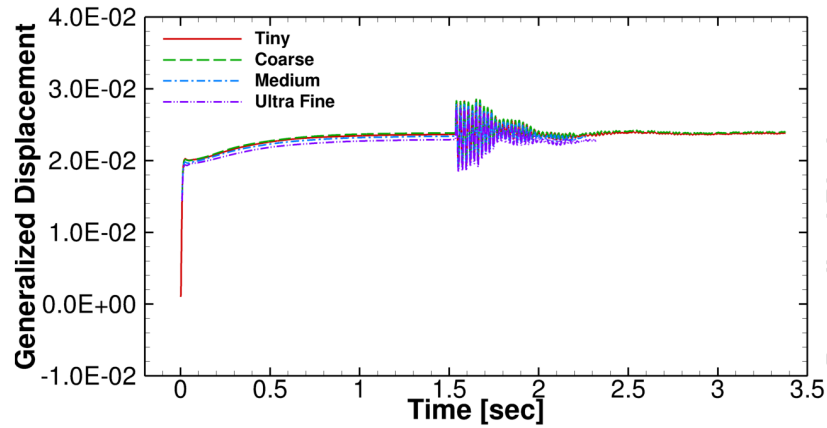

(c) Mode 13: $46.3 \mathrm{~Hz}$, high lift nacelle pitch, wing 3rd bending

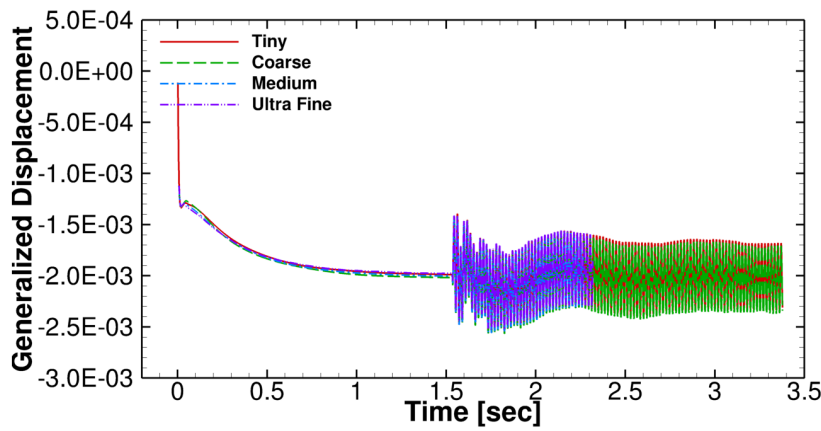

(e) Mode 15: $55.5 \mathrm{~Hz}$, high lift nacelle pitch

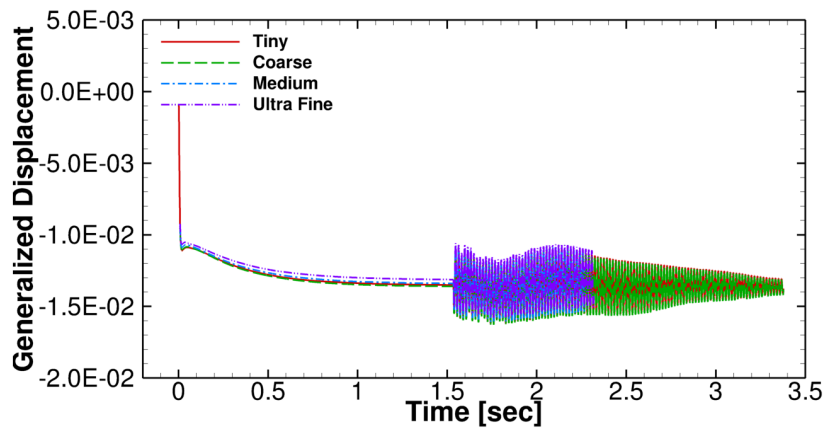

(g) Mode 17: $59.5 \mathrm{~Hz}$, high lift nacelle pitch

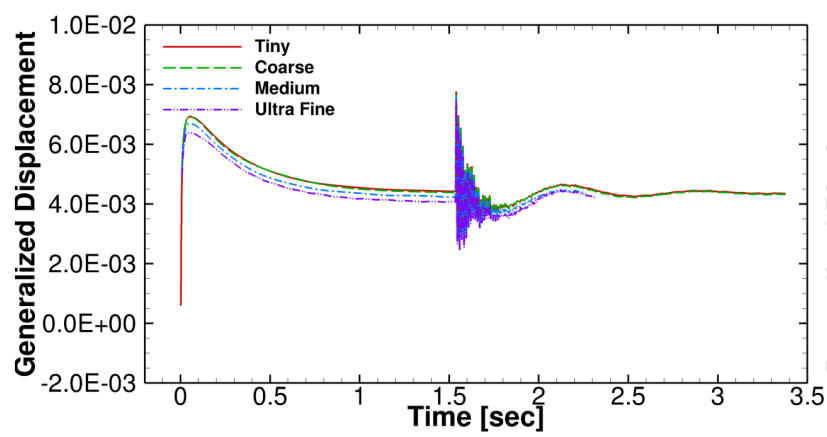

(i) Mode 19: $83.2 \mathrm{~Hz}$

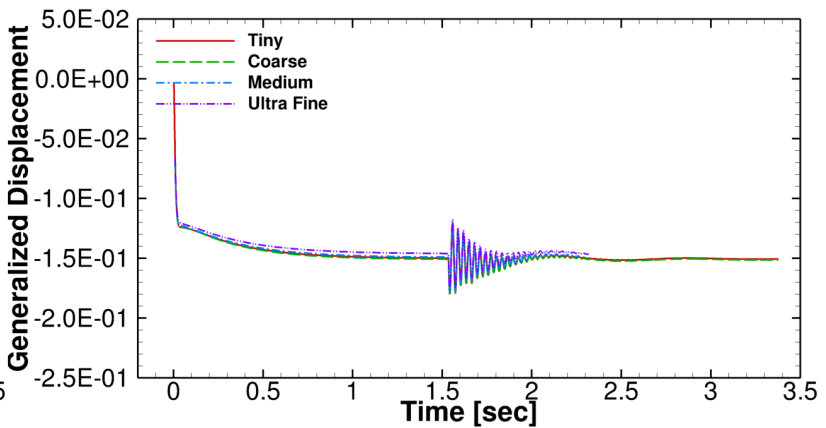

(b) Mode 12: $33.0 \mathrm{~Hz}$, high lift nacelle pitch, wing 2nd torsion

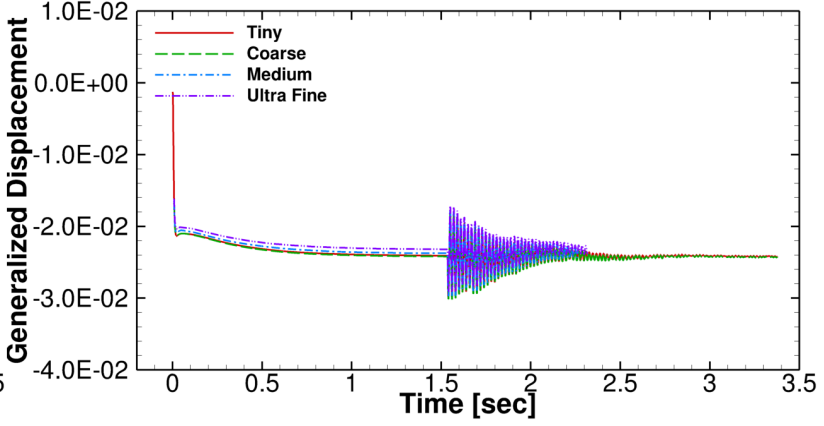

(d) Mode 14: $50.7 \mathrm{~Hz}$, high lift nacelle pitch, wing 3rd torsion

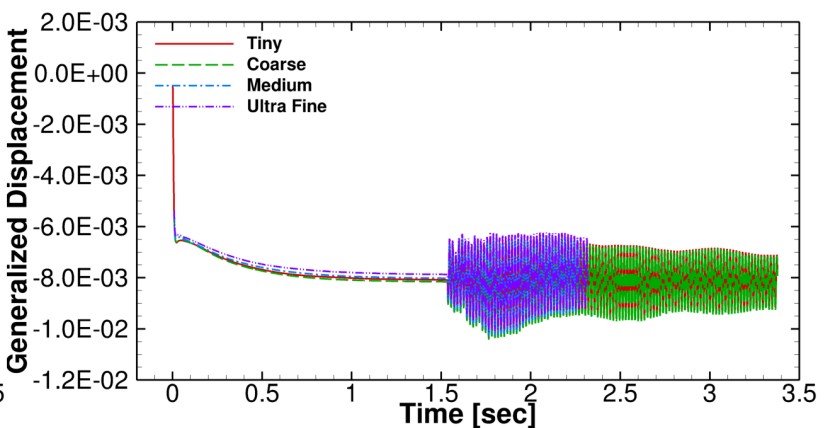

(f) Mode 16: $57.6 \mathrm{~Hz}$, high lift nacelle pitch

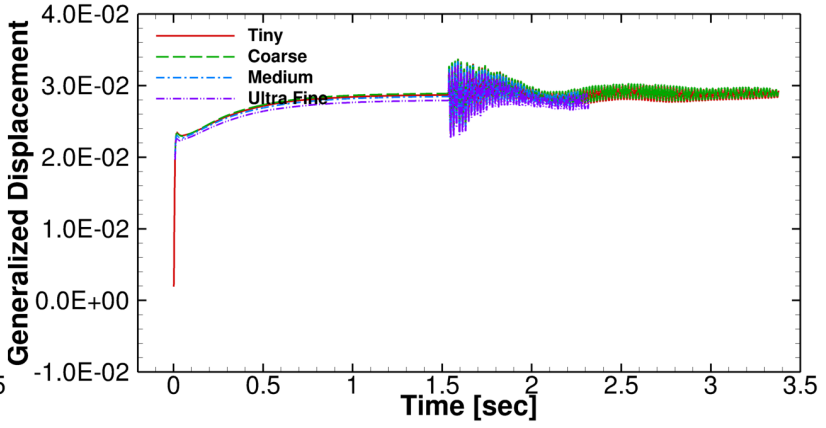

(h) Mode 18: $60.3 \mathrm{~Hz}$, high lift nacelle pitch

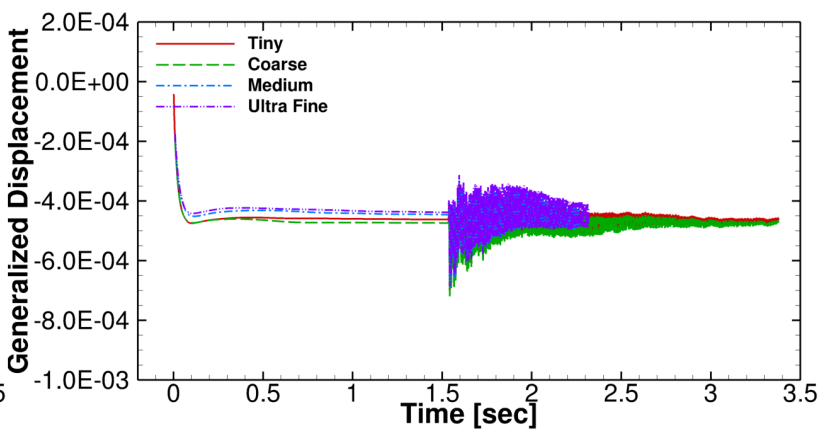

(j) Mode 20: $124.9 \mathrm{~Hz}$

Figure 14 (Cont.): $q=1.748$ psi: Grid convergence of static and dynamic modal response for perturbation type 1. 


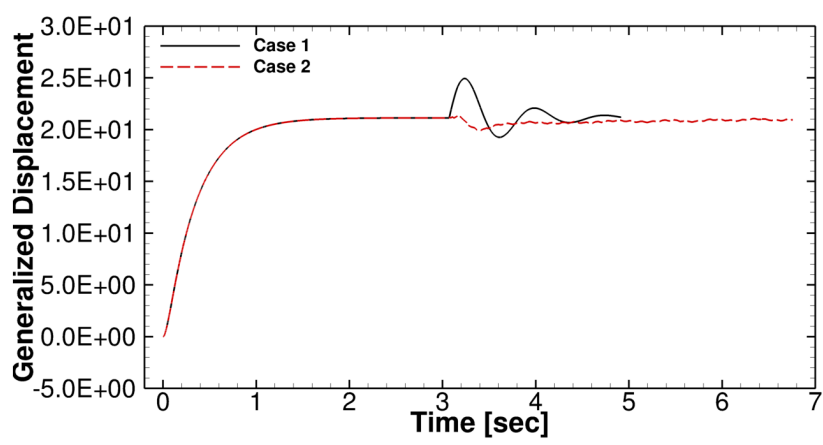

(a) Mode 1: $1.8 \mathrm{~Hz}$, wing 1st bending

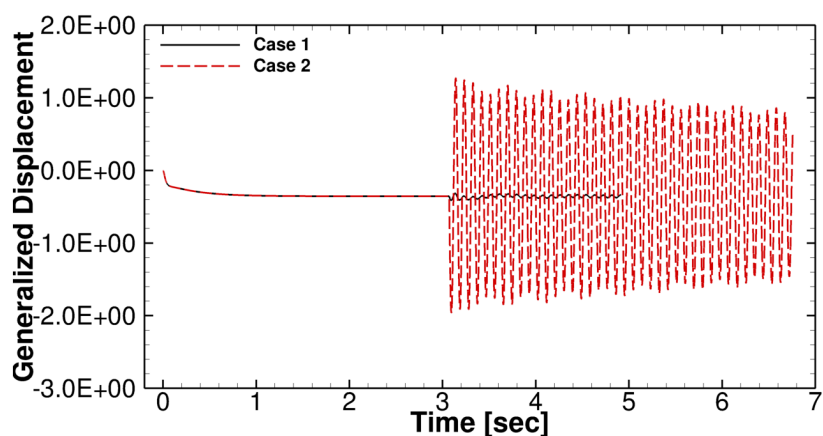

(c) Mode 3: $10.8 \mathrm{~Hz}$, tip nacelle yaw

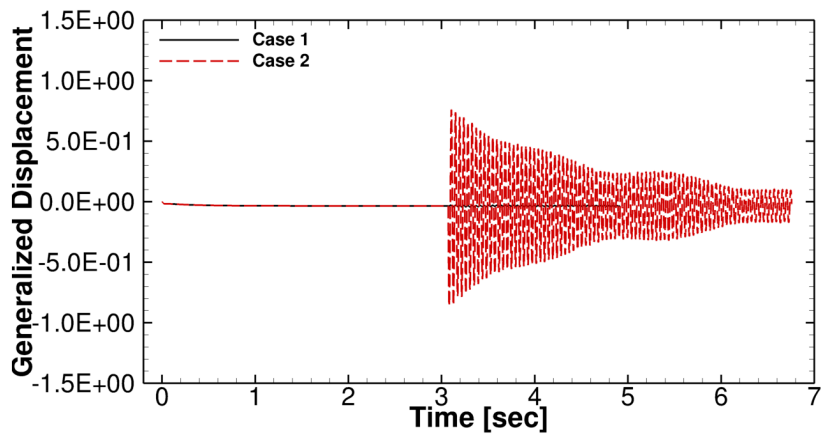

(e) Mode 5: $22.6 \mathrm{~Hz}$, high lift nacelle yaw

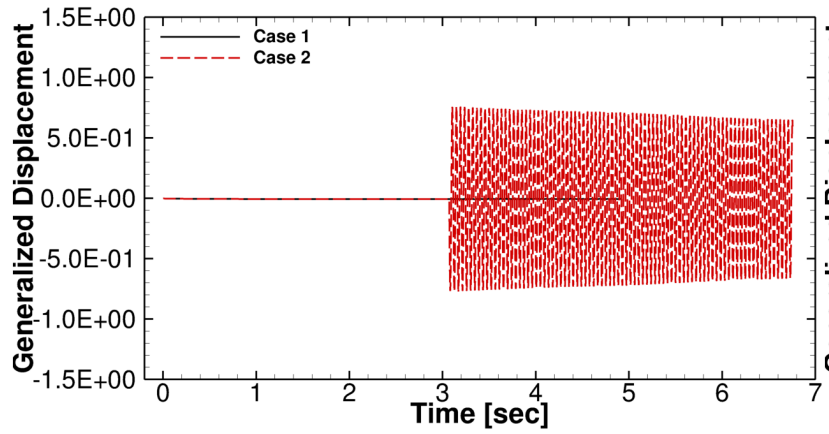

(g) Mode 7: $22.9 \mathrm{~Hz}$, high lift nacelle yaw

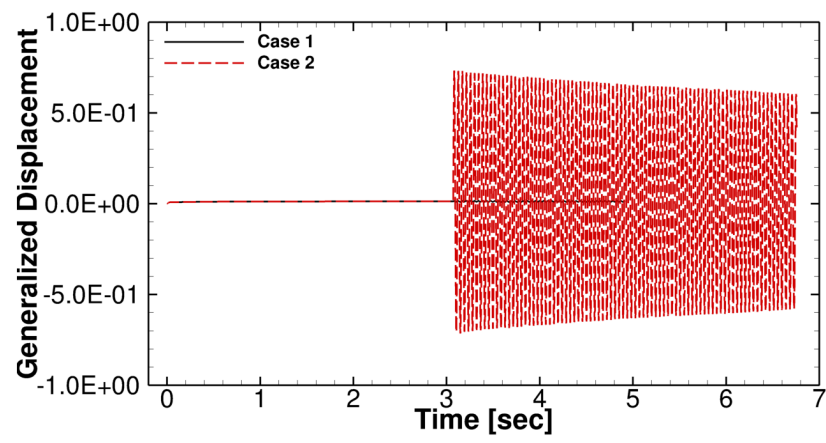

(i) Mode 9: $23.0 \mathrm{~Hz}$, high lift nacelle yaw

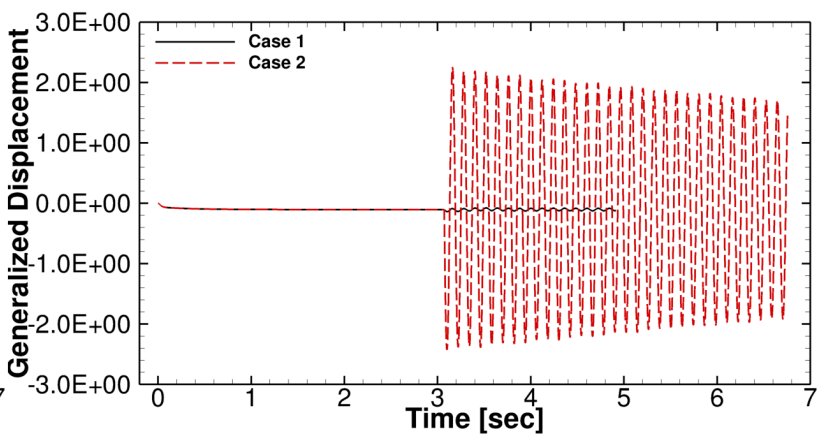

(b) Mode 2: $8.4 \mathrm{~Hz}$, wing 1st in-plane bending

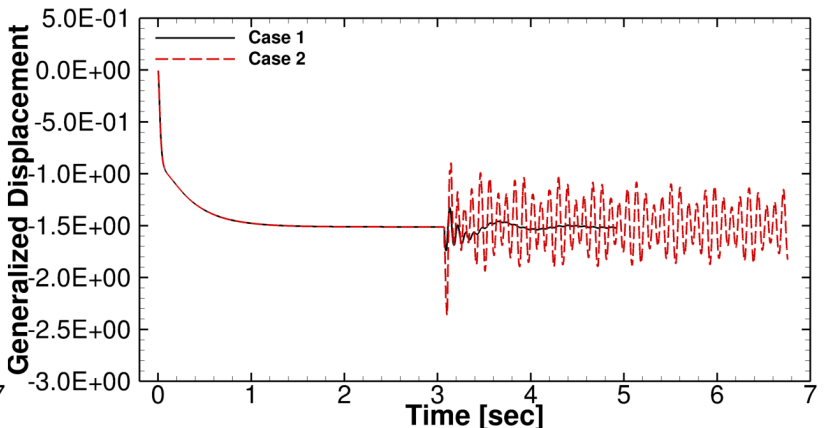

(d) Mode 4: 11.4 Hz, wing 2nd bending, wing 1st torsion

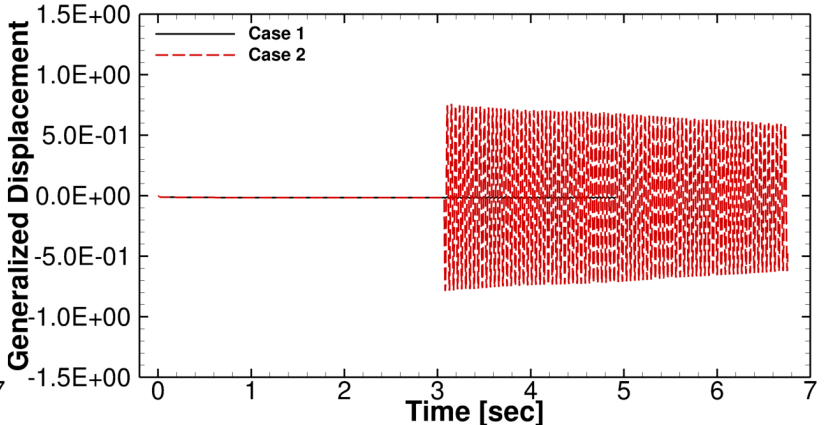

(f) Mode 6: $22.8 \mathrm{~Hz}$, high lift nacelle yaw

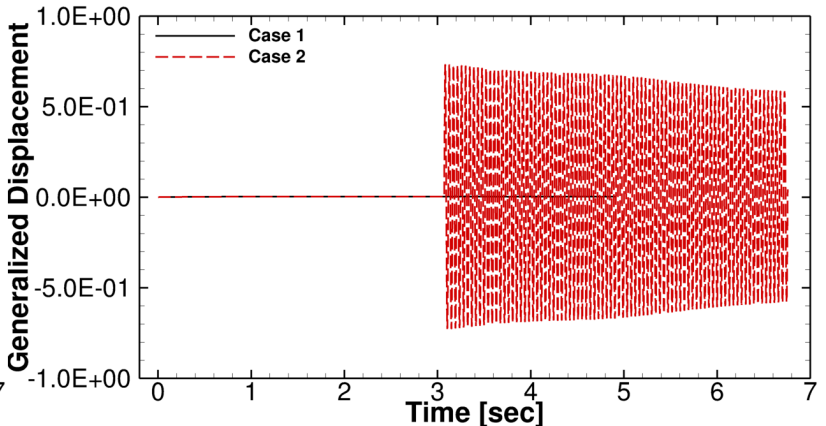

(h) Mode 8: $22.9 \mathrm{~Hz}$, high lift nacelle yaw

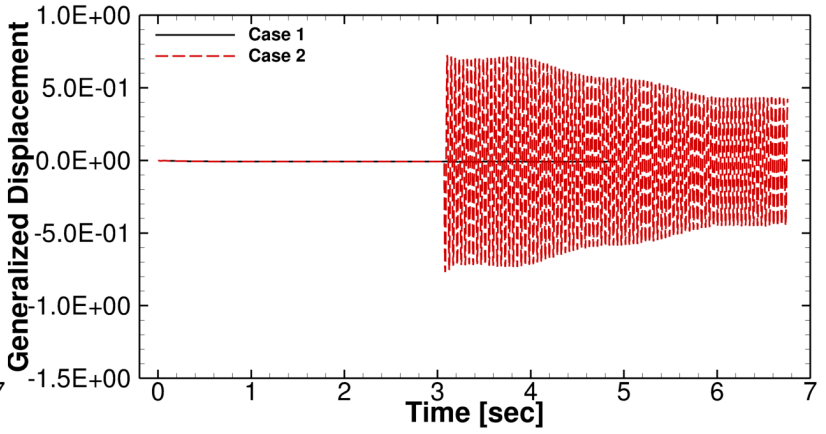

(j) Mode 10: $23.4 \mathrm{~Hz}$, high lift nacelle yaw

Figure 15: $q=1.748$ psi: Static and dynamic modal response for perturbation type 1 and 2 on tiny mesh.

18 of 20 


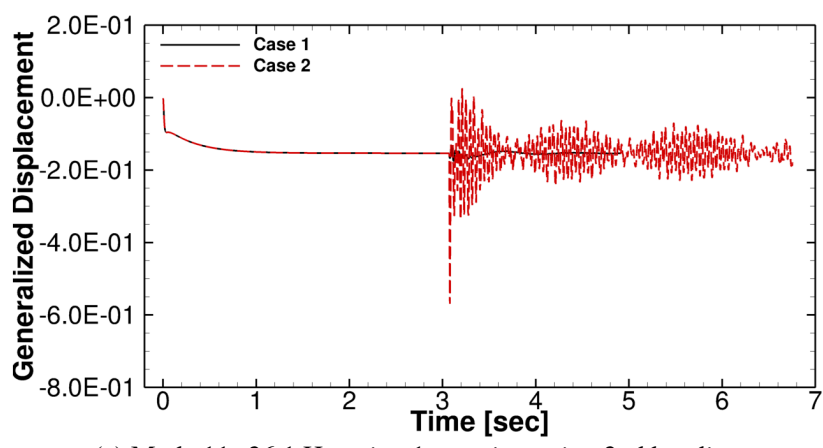

(a) Mode 11: $26.1 \mathrm{~Hz}$, wing 1st torsion, wing 2nd bending

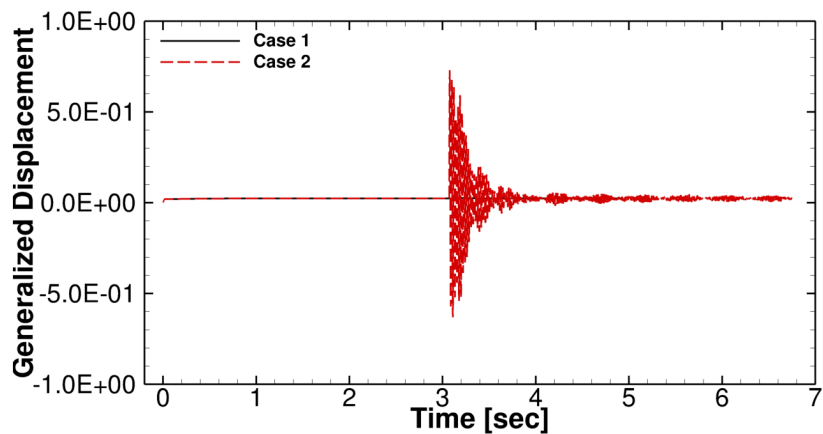

(c) Mode 13: $46.3 \mathrm{~Hz}$, high lift nacelle pitch, wing 3rd bending

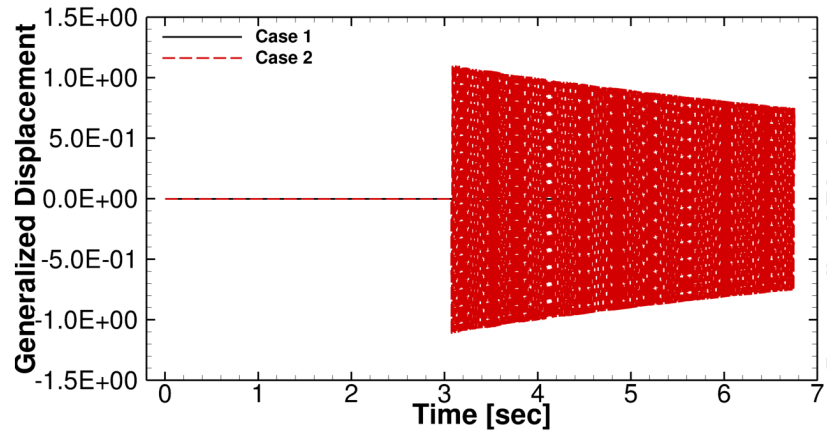

(e) Mode 15: $55.5 \mathrm{~Hz}$, high lift nacelle pitch

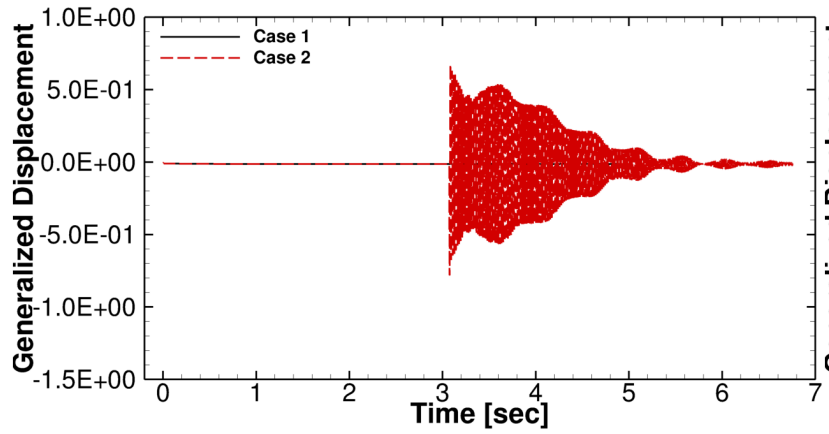

(g) Mode 17: $59.5 \mathrm{~Hz}$, high lift nacelle pitch

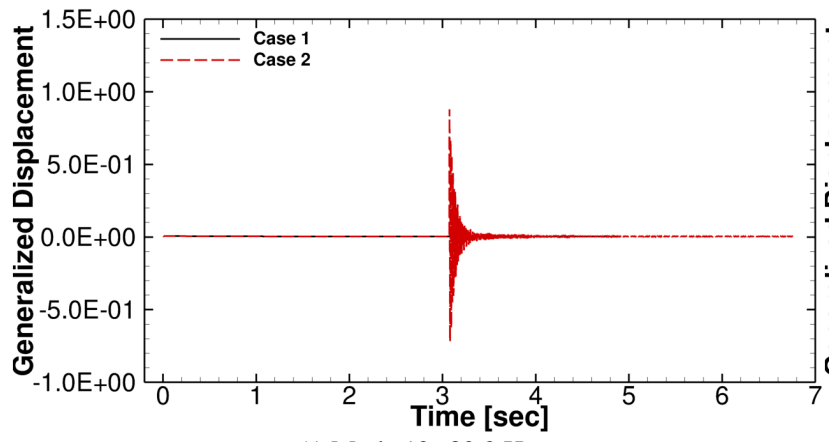

(i) Mode 19: $83.2 \mathrm{~Hz}$

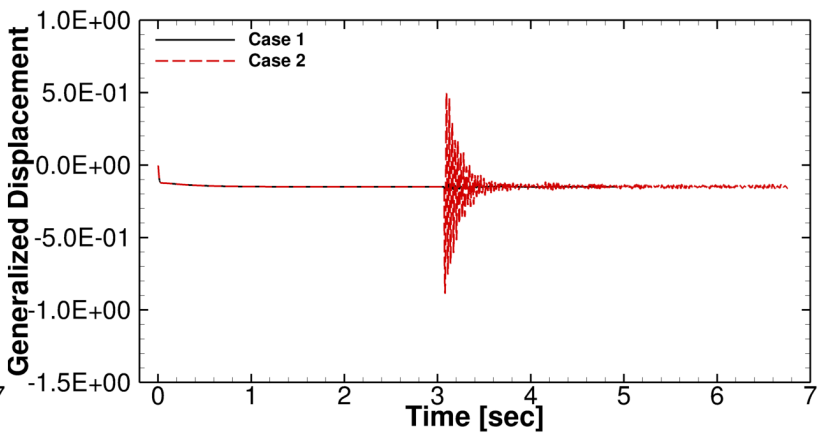

(b) Mode 12: $33.0 \mathrm{~Hz}$, high lift nacelle pitch, wing 2nd torsion

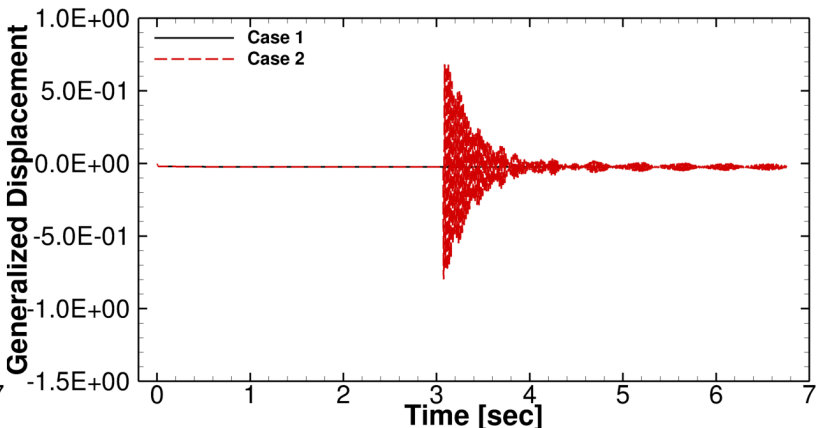

(d) Mode 14: $50.7 \mathrm{~Hz}$, high lift nacelle pitch, wing 3rd torsion

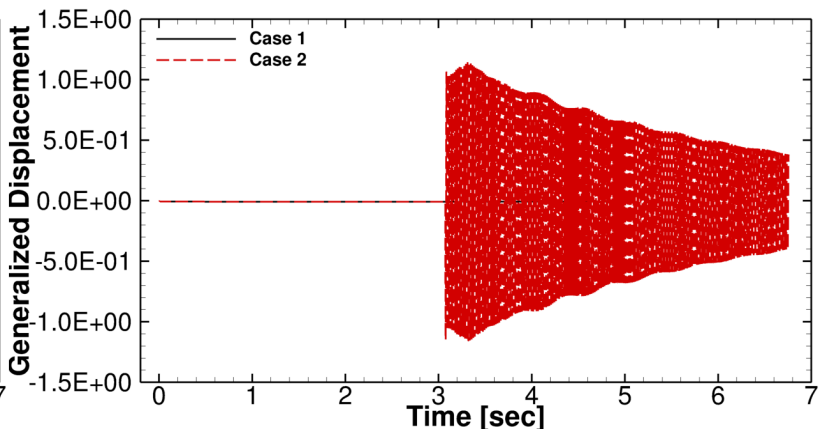

(f) Mode 16: $57.6 \mathrm{~Hz}$, high lift nacelle pitch

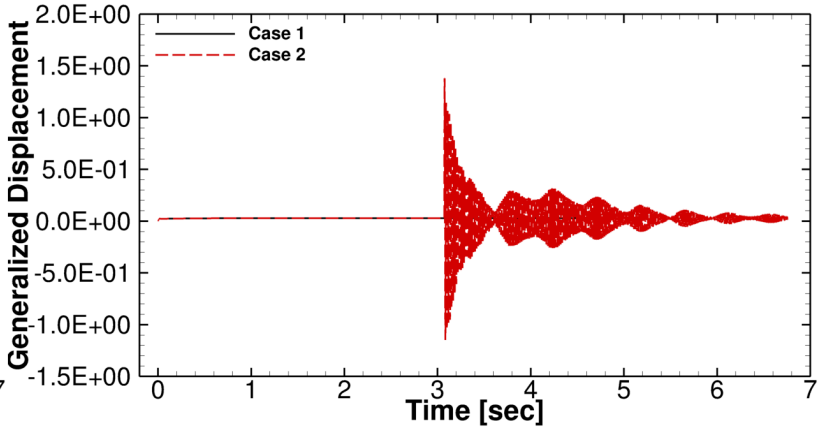

(h) Mode 18: $60.3 \mathrm{~Hz}$, high lift nacelle pitch

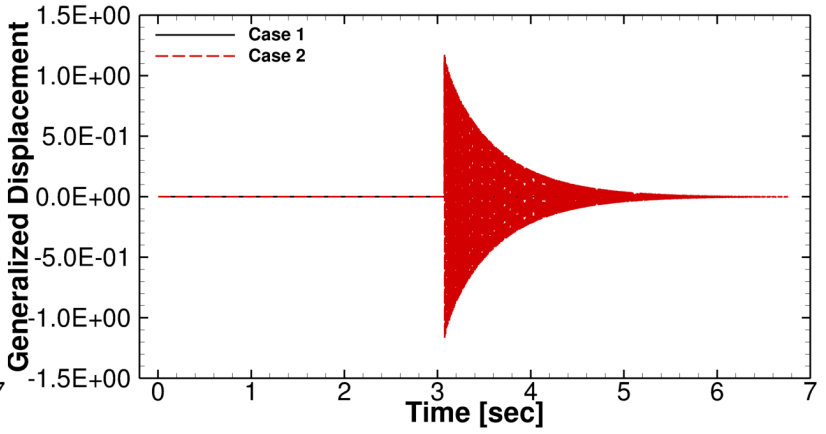

(j) Mode 20: $124.9 \mathrm{~Hz}$

Figure 15 (Cont.): $q=1.748$ psi: Static and dynamic modal response for perturbation type 1 and 2 on tiny mesh. 


\section{Concluding Remarks}

A wing aeroelastic analysis of a distributed electric propulsion wing using linear and nonlinear aerodynamics was presented. It was found that no dynamic instability existed, only that of divergence, which occurred in the first bending mode at a dynamic pressure of over three times the flutter clearance condition. Four levels of grid refinement were examined for the FUN3D solutions and solutions were seen to be well converged. The coarsest mesh solution for force and moment coefficients at the highest dynamic pressure, differed from the finest by $3 \%$ or less and produced a nearly identical dynamic response, thus the the tiny mesh is well suited to evaluate gross parameter influences. Aeroelastic results using Nastran doublet lattice aerodynamics compared well to those based on FUN3D Reynolds-Averaged Navier-Stokes aerodynamics for lift and tip displacements, however, were significantly different for pitching moment. In future studies, the use of aerodynamic correction factors computed from CFD and applied to Nastran solutions will be investigated. FUN3D detected areas of flow separation at the pylon wing junctions and as the outer mold line is refined, this will continue to be an area that will need to be monitored with RANS aerodynamics for any possible aeroelastic excitations.

\section{References}

1“NASA X-57 Maxwell,” URL:https://en.wikipedia.org/wiki/NASA_X-57_Maxwell, [cited 5 Oct 2016].

${ }^{2}$ Warwick, G., "NASA's Electric-Propulsion Wing Test Helps Shape Next X-Plane," [cited 24 August 2015], URL: http://aviationweek . com/technology/nasa-s-electric-propulsion-wing-test-helps-shape-next-x-plane.

${ }^{3}$ Moore, M. D. and Fredericks, W. J., "Misconceptions of Electric Aircraft and their Emerging Aviation Markets," AIAA Paper 2014-0535, Jan. 2014.

${ }^{4}$ Borer, N. K., Nickol, C. L., Jones, F. P., Yasky, R. J., Woodham, K., Fell, J. S., Litherland, B. L., Loyselle, P. L., Provenza, A. J., Kohlman, L. W., and Samuel, A. G., "Overcoming the Adoption Barrier to Electric Flight," AIAA Paper 2016-1022, Jan. 2016.

${ }^{5}$ Patterson, M. D., Borer, N. K., and German, B. J., "A Simple Method for High-Lift Propeller Conceptual Design," AIAA Paper 2016-0770, Jan. 2016.

${ }^{6}$ Patterson, M. D., Derlaga, J. M., and Borer, N. K., "High-Lift Propeller System Configuration Selection for NASA's SCEPTOR Distributed Electric Propulsion Flight Demonstrator,” AIAA Paper 2016-3922, June 2016.

${ }^{7}$ Stoll, A. M., Bevirt, J., Moore, M. D., Fredericks, W. J., and Borer, N. K., "Drag Reduction Through Distributed Electric Propulsion," AIAA Paper 2014-2851, June 2014.

${ }^{8}$ David M. O'Brien, J., Analysis of Computational Modeling Techniques for Complete Rotorcraft Configurations, Ph.D. dissertation, Georgia Institute of Technology, Georgia, May 2006.

${ }^{9}$ Biedron, R. T. and Lee-Rausch, E. M., "Rotor Airloads Prediction Using Unstructured Meshes and Loose CFD/CSD Coupling," AIAA Paper 2008-7341, Aug. 2008.

${ }^{10}$ MSC Software Corporation, Newport Beach, CA, MSC Nastran 2014.1 Release Guide, 2014.

${ }^{11}$ Rodden, W. P., Taylor, P. F., McIntosh, S. C., and Baker, M. L., "Further Convergence Studies of the Enhanced Doublet-Lattice Method," Journal of Aircraft, Vol. 36, No. 4, 1999, pp. 682-688.

${ }^{12}$ Pointwise, Inc., Fort Worth, Texas, Pointwise V17.3R3 User Manual, 2015.

13 “DPW6 Gridding Guidelines," URL:http://aiaa-dpw.larc.nasa.gov/Workshop6/grids.html, [cited 28 Aug 2015].

${ }^{14}$ Biedron, R. T., Carlson, J., Derlaga, J. M., Gnoffo, P. A., Hammond, D. P., Jones, W. T., Kleb, B., Lee-Rausch, E. M., Nielsen, E. J., Park, M. A., Rumsey, C. L., Thomas, J. L., and Wood, W. A., "FUN3D Manual: 12.9,” NASA TM 2016-219012, Feb. 2016.

${ }^{15}$ Spalart, P. R. and Allmaras, S. R., “A One-Equation Turbulence Model for Aerodynamic Flows," La Recherche Aerospatiale, No. 1, 1994, pp. $5-21$

${ }^{16}$ Spalart, P. R., "Strategies for Turbulence Modelling and Simulations," International Journal of Heat and Fluid Flow, Vol. 21, No. 3, 2000, pp. $252-263$.

${ }^{17}$ Shur, M. L., Strelets, M. K., Travin, A. K., and Spalart, P. R., "Turbulence Modeling in Rotating and Curved Channels: Assessing the Spalart-Shur Correction," AIAA Journal, Vol. 38, No. 5, 2000, pp. 784-792.

${ }^{18}$ Roe, P. L., "Approximate Riemann Solvers, Parameter Vectors, and Difference Schemes," Journal of Computational Physics, Vol. 43, 1981, pp. 357-372.

${ }^{19}$ Nyukhtikov, M., Smelova, N., Mitchell, B. E., and Holmes, D. G., "Optimized Dual-Time Stepping Technique For Time-Accurate NavierStokes Calculations," Proceedings of the 10th International Symposium on Unsteady Aerodynamics, Aeroacoustics and Aeroelasticity of Turbomachines, 2003.

${ }^{20}$ Vatsa, V. N., Carpenter, M. H., and Lockard, D. P., "Re-evaluation of an Optimized Second Order Backward Difference (BDF2OPT) Scheme for Unsteady Flow Applications," AIAA Paper 2010-0122, Jan. 2010.

${ }^{21}$ Thomas, P. D. and Lombard, C. K., "Geometrical Conservation Law and Its Application," AIAA Journal, Vol. 17, No. 10, Oct. 1978, pp. 1030-1037.

${ }^{22}$ Biedron, R. T. and Thomas, J. L., "Recent Enhancements To The FUN3D Flow Solver For Moving-Mesh Applications," AIAA Paper 2009-1360, Jan. 2009.

${ }^{23}$ Cunningham, H. J., Batina, J. T., and Bennett, R. M., "Modern wing flutter analysis by computational fluid dynamics methods," Journal of Aircraft, Vol. 25, No. 10, 1988, pp. 962-968.

${ }^{24}$ Rendall, T. and Allen, C., "Efficient Mesh Motion Using Radial Basis Functions with Data Reduction Algorithms," Journal of Computational Physics, Vol. 228, 2009, pp. 6231-6249.

${ }^{25}$ Silva, W. A., Chwalowski, P., and Perry, III, B., "Evaluation of linear, inviscid, viscous, and reduced-order modelling aeroelastic solutions of the AGARD 445.6 wing using root locus analysis," International Journal of Computational Fluid Dynamics, Vol. 28, No. 3-4, 2014 , pp. 122-139.

20 of 20 